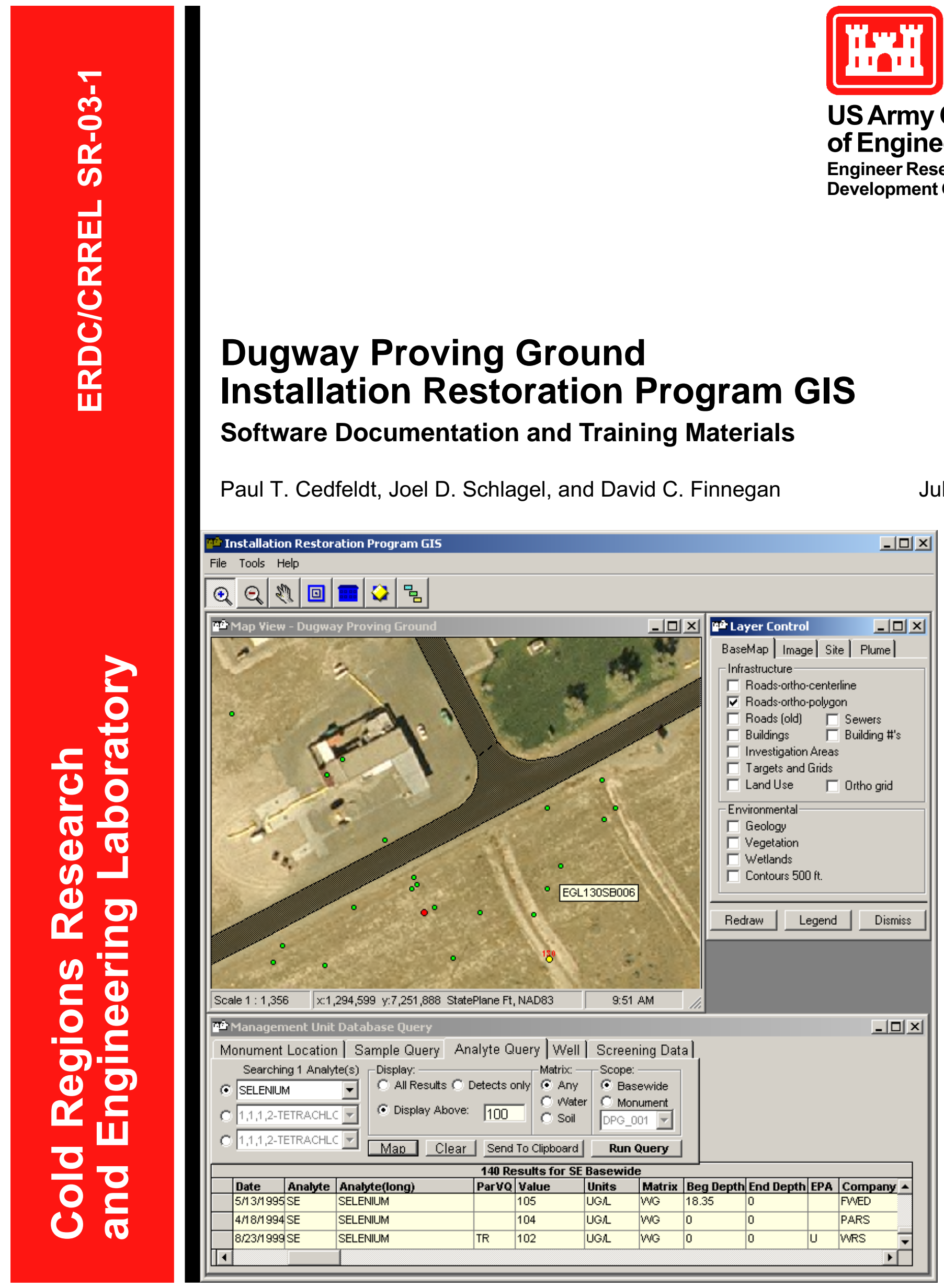

Approved for public release; distribution is unlimited. 
Front cover: The Dugway Installation Restoration GIS in action. 


\section{Dugway Proving Ground Installation Restoration Program GIS}

\section{Software Documentation and Training Materials}

Paul T. Cedfeldt, Joel D. Schlagel, and David C. Finnegan

Cold Regions Research and Engineering Laboratory

72 Lyme Road

Hanover, New Hampshire 03755

Approved for public release; distribution is unlimited. 


\begin{abstract}
At the request of U.S. Army Dugway Proving Ground's Installation Restoration Program, the U.S. Army Engineer Research and Development Center's Cold Regions Research and Engineering Lab developed a Geographic Information System (GIS) for management and analysis of environmental restoration data. The GIS software can be used to compare and analyze datasets of diverse types, e.g., orthophotos, contaminant information stored in a database, and geospatial datalayers such as sample locations, roads, and buildings. Powerful chemical query capabilities allow the user to search for analytical results either basewide or at a particular site. Users can also query one or multiple contaminants by a specific detection threshold level, or return all sample results regardless of detection level. Query results can then be mapped to the screen to highlight clusters and/or possible contamination trends, or exported to a spreadsheet program. Hard-copy maps can also be printed from the software.
\end{abstract}

DISCLAIMER: The contents of this report are not to be used for advertising, publication, or promotional purposes. Citation of trade names does not constitute an official endorsement or approval of the use of such commercial products. All product names and trademarks cited are the property of their respective owners. The findings of this report are not to be construed as an official Department of the Army position unless so designated by other authorized documents. 


\section{CONTENTS}

Conversion factors, non-SI to SI units of measurement ……............................. V

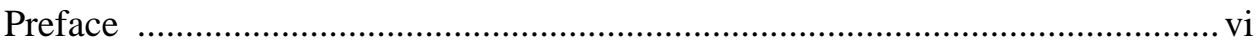

1 DPG Installation Restoration Program GIS (DPG-GIS) ............................... 1

2 Installing DPG-GIS Software for the First Time .......................................... 3

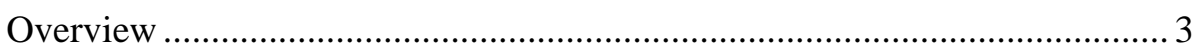

What do you need before you start?............................................................ 3

System requirements .......................................................................... 3

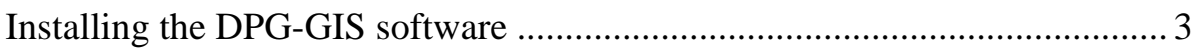

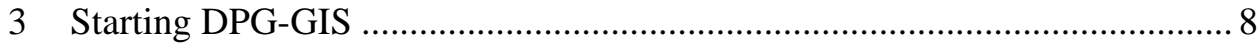

4 DPG-GIS Main Menu and Control Buttons ................................................ 10

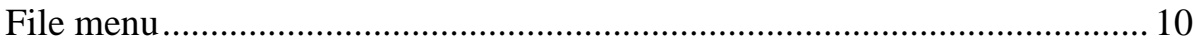

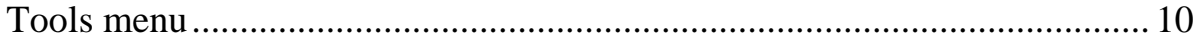

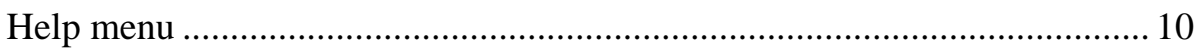

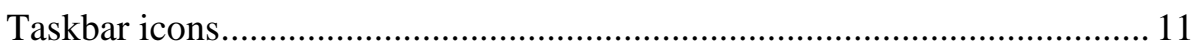

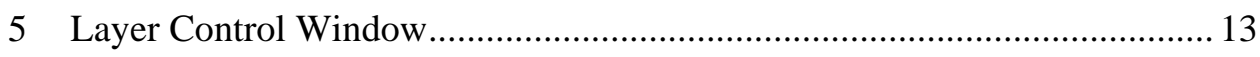

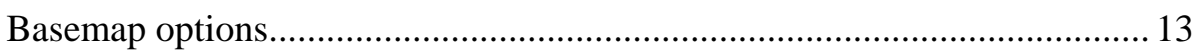

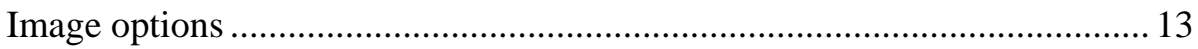

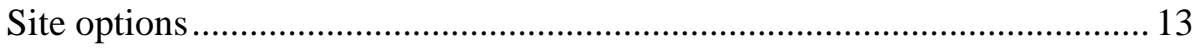

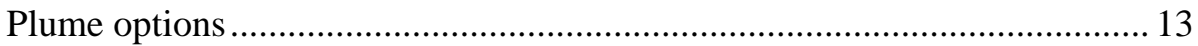

6 Management Unit Database Query Window............................................... 15

Monument Location tab ............................................................................. 15

Sample Query tab ................................................................................ 16

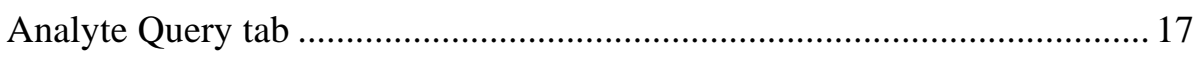

Well Information tab ......................................................................... 18

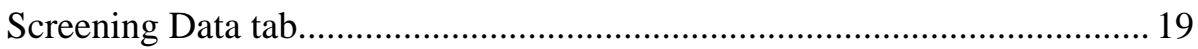

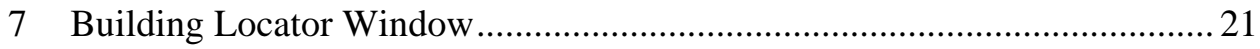

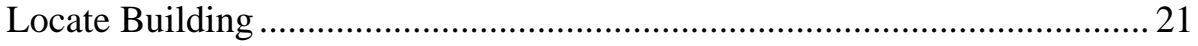

Appendix A. Exercises and Examples ............................................................. 22 


\section{ILLUSTRATIONS}

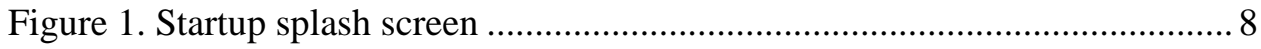

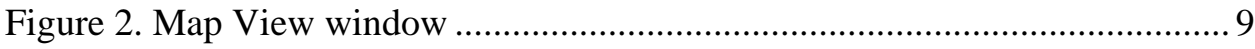

Figure 3. Main program taskbar..................................................................... 10

Figure 4. Pulldown menus available from the main taskbar................................ 11

Figure 5. Overview of the DPG-GIS layout with Layer Control and Management Unit Database Query windows activated .......................... 12

Figure 6. Layer Control and Legend windows .................................................. 14

Figure 7. Monument Location tab overview.................................................... 15

Figure 8. Sample Query tab overview ............................................................ 16

Figure 9. Analyte Query tab overview............................................................. 17

Figure 10. Well Info tab overview …................................................................ 18

Figure 11. Building Locator window ................................................................ 21 


\section{CONVERSION FACTORS, NON-SI TO} SI UNITS OF MEASUREMENT

Non-SI units of measurement used in this report can be converted to SI units as follows:

\begin{tabular}{|l|c|l|}
\hline Multiply & By & To obtain \\
\hline acres & $4,046.873$ & square meters \\
\hline miles (U.S. statute) & 1.609347 & kilometers \\
\hline
\end{tabular}




\section{PREFACE}

This report was prepared by Paul T. Cedfeldt, Physical Scientist, Joel D. Schlagel, Research Physical Scientist, and David C. Finnegan, Contractor, Remote Sensing and GIS Branch, Engineer Research and Development Center (ERDC), U.S. Army Cold Regions Research and Engineering Laboratory (CRREL), Hanover, New Hampshire.

Funding was provided by U.S. Army Dugway Proving Ground Installation Restoration Program, Dugway, Utah.

The authors thank Scott Reed, Dugway Restoration Program Manager, for funding software development and enabling CRREL to contribute to the restoration efforts at Dugway. Thanks also to Keller Davis, Tetra-Tech EM, Inc., for thoughtful and timely user feedback that helped to improve the software. Finally, thanks to Tim Pangburn, Chief, Remote Sensing and GIS Branch, for providing guidance and funds for editing this report.

The Commander of the Engineer Research and Development Center is Colonel James R. Rowan, EN. The Director is Dr. James R. Houston. 


\title{
Dugway Proving Ground Installation Restoration Program GIS Software Documentation and Training Materials
}

\author{
PAUL T. CEDFELDT, JOEL D. SCHLAGEL, AND DAVID C. FINNEGAN
}

\section{DPG INSTALLATION RESTORATION PROGRAM GIS (DPG-GIS)}

At the request of Dugway Proving Ground's Installation Restoration Program, the U.S. Army Engineer Research and Development Center's Cold Regions Research and Engineering Laboratory (ERDC-CRREL) has developed a Geographic Information System (GIS) for management and analysis of environmental remediation efforts. Dugway Proving Ground (DPG) is the nation's primary chemical and biological defense testing facility and is located on 798,855 acres in the Great Salt Lake Desert, approximately 85 miles southwest of Salt Lake City, Utah. Surrounded on three sides by mountain ranges, the proving ground's terrain varies from level salt flats to scattered sand dunes and rugged mountains.

DPG was activated on March 1, 1942. Shortly thereafter, military weapons testing commenced under the Technical Division of the U.S. Chemical Corps. There are 21 test ranges at the proving ground. Numerous chemical munitions and microorganisms were tested during the 1940s and 1950s. Large-scale conventional munitions testing was also conducted at the ranges until the late 1970s. Historical waste disposal practices have generated possible contamination at 205 Solid Waste Management Units (SWMUs) and at an additional 41 Hazardous Waste Management Units (HWMUs) that ceased operation after 1980. From a regulatory perspective, contaminants of concern are agents (HD, L, VX, GB, BZ, GD), agent breakdown products, caustics, solvents, metals, volatiles, pesticides, PCBs, and POLs.

Many sites located in the test ranges are being investigated by the Installation Restoration Program. The large volume of data being generated for these projects by various engineering consultants and other contractors lends itself to the use of 
GIS software to manage the data. GIS provides the means to store, display, and analyze information from multiple diverse sources in one, two, and three dimensions. Effective data management is critical given the scale and complexity of the DPG environmental investigations. Although large amounts of data have been generated, much of it had resided in separate locations. Making a common database of chemical sampling results was the first step toward creating the GIS. A common geospatial database was also created, bringing together various vector datalayers and raster imagery. A customized, easy-to-use graphical interface was then written to access and analyze these data. There is a Windows desktop version as well as an Internet-accessible version that runs in a Web browser. Project managers can now use the GIS software via either platform to compare and analyze datasets of diverse types, e.g., orthophotos, contaminant information stored in a database, and geospatial datalayers such as sample locations, roads, and buildings. Powerful chemical query capabilities allow any user to search for analytical results either basewide or at a particular SWMU or HWMU. Project managers can query one or multiple contaminants by a specific detection threshold level, or return all sample results regardless of detection level. A typical query might involve searching for selenium samples taken anywhere on DPG that yielded a result greater than $100 \mu \mathrm{g} / \mathrm{L}$. Query results can then be mapped to the screen to highlight clusters and/or possible contamination trends, or sent out to a spreadsheet program. Hard-copy maps can also be printed.

The Installation Restoration Program GIS also protects current and future data investments. By making these data available to contractors prior to their undertaking new projects, there exists a significant potential to reduce redundancy in data acquisition.

Scott Reed, Installation Restoration Program Manager at DPG, states emphatically, "The GIS developed by ERDC saves me time and makes my operations more efficient. A contaminant sample query that had previously taken several calls to different contractors and several days in execution time now takes, in most cases, under a minute. We are extremely pleased with the Corps' GIS software product.”

This state of the art Geographic Information System software for accessing, displaying, and analyzing DPG installation restoration data was developed by the Remote Sensing/GIS Center at ERDC-CRREL using object technologies from commercial GIS and Database vendors. 


\section{INSTALLING DPG-GIS SOFTWARE FOR THE FIRST TIME}

\section{Overview}

This section describes the procedure for a stand-alone installation of the DPG-GIS software on a Windows operating system.

What do you need before you start?

- DPG-GIS Version 2.0 Installation CD

- This guide

\section{System requirements}

DPG-GIS is distributed on ISO9660 format CD-ROMs. DPG-GIS software may not be copied or distributed without express written permission.

Microsoft Windows-Recommended

- Windows 98, NT, 2000, XP

- Pentium II 450-mhz processor, or greater

- CD-ROM drive

- $\quad 3.7$ GB of free hard disk space, plus space for user reports

- $128 \mathrm{MB}$ of RAM, or greater

Installing the DPG-GIS software

In order for the DPG-GIS software to run properly, Microsoft Database Access Objects (DAO) software must be installed. When this manual was written, the current version of DAO was version 3.5. A copy of the DAO installation program is included on the DPG-GIS installation disk.

To install or update the existing DAO software on your machine, perform the following steps:

1. Insert the DPG-GIS software CD into your CD-Rom drive.

2. Navigate to the Start menu and click Run. The run dialog box opens. 
3. In the Open text box type

D:\miscellaneous $\backslash$ DAO35.EXE

where $\mathrm{D}: \backslash$ is the letter of the default CD-ROM drive. You can also locate DAO35.EXE via the Browse button.

The install shield wizard will then direct you through the rest of the installation process.

To install the DPG-GIS software using the Install Wizard, perform the following steps:

1. Insert the DPG-GIS software CD into your CD-ROM drive.

If Autorun has been enabled for your CD-Rom drive, the install wizard starts automatically.

2. If the install wizard does not start automatically, click Run on the Start menu. The run dialog box opens.

In the Open text box, type

D:Isetup.exe

where D: is the letter of the default CD-ROM drive. You can also locate setup.exe via the Browse button.

The install wizard will display a progress monitor and gives you the following options:

- $\mathrm{OK}$-Proceed to the next step.

- Exit Setup-Discontinue setup and Exit.

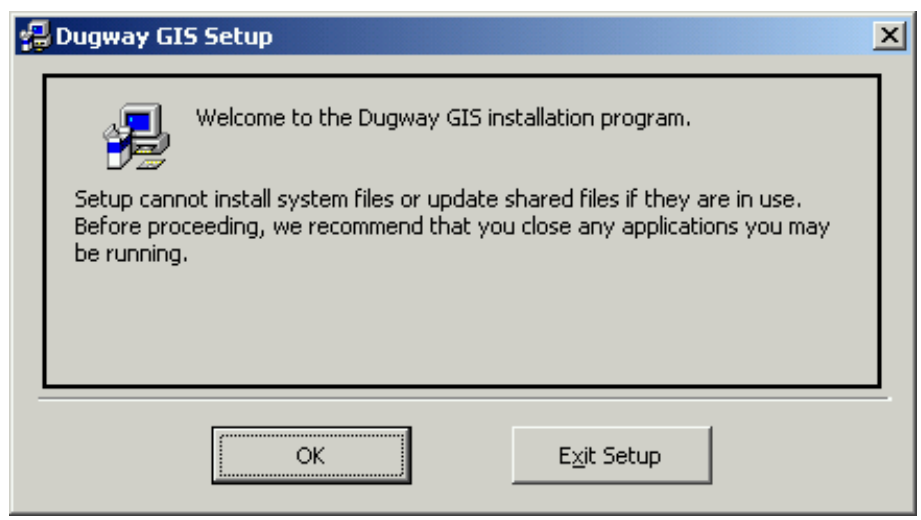

3. To proceed to the next step, click OK. 
Assigning a destination folder

1. Select the destination folder for the DPG-GIS software.

The default drive location should be

C: Program Files\DugwayGIS $\backslash$.

2. If you wish to install in a different directory, click the Change Directory button and enter a new location.

3. After you are finished, click the Computer icon to install to the specified location.

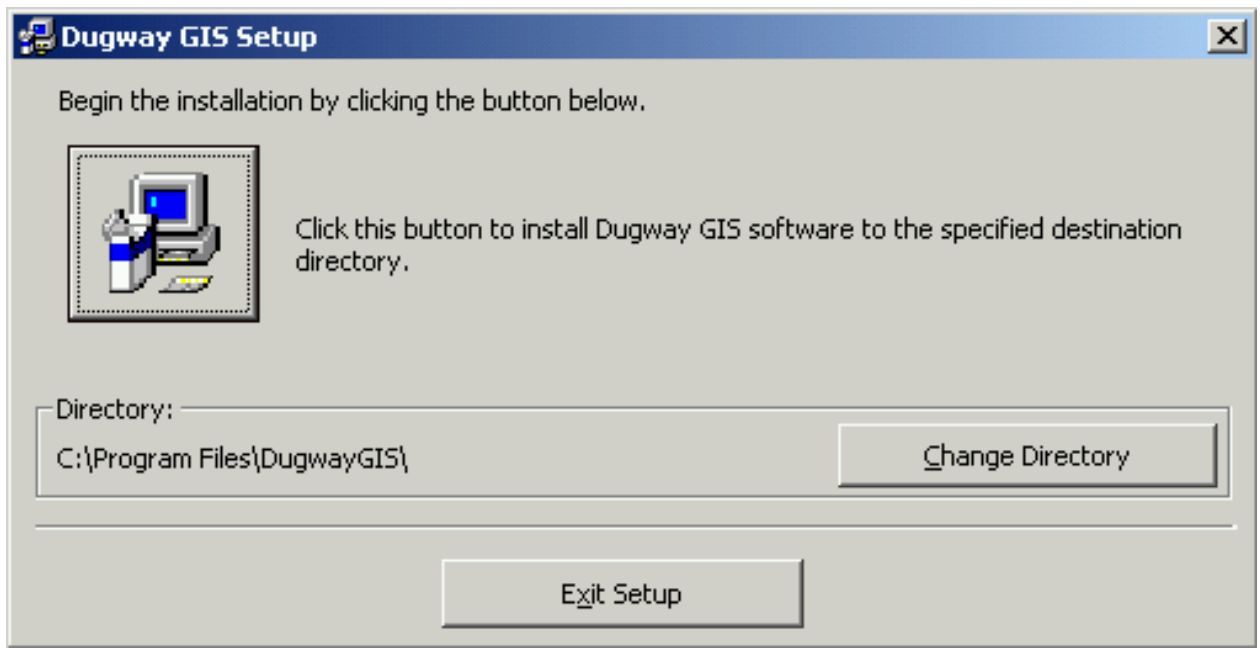

Choosing a program group

In this dialog box, you are prompted to choose a program group to add to the Start menu. The default Group is Dugway Proving Grounds GIS.

1. Click Continue to finish. 


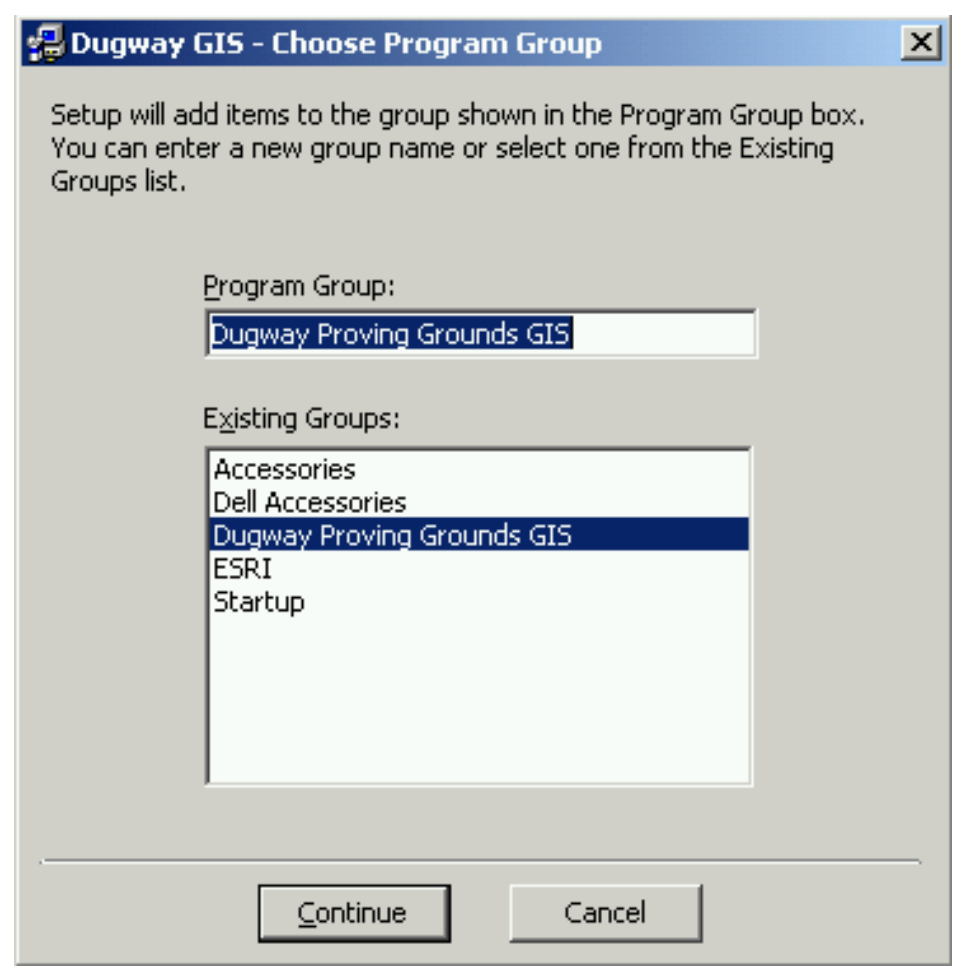

A Progress box appears and indicates the status of the installation process until complete.

Installing the data

In order for the program to run properly, the Chemical, GIS, and imagery databases must be transferred to the install directory from the installation disk.

1. Insert the DPG-GIS installation disk into the CD-ROM drive.

2. Go to the Start menu and open Microsoft Windows Explorer (found under the Program-Accessories menu).

3. In Windows Explorer navigate to the CD-ROM drive and copy the following data folders from the disk:

- 3dModel

- Data

- Images

- Mocovers 
4. Paste the folders into the C: $\backslash$ Program Files\DugwayGIS Directory.

5. Remove the DPG-GIS software CD and insert the next imagery $\mathrm{CD}$ into the drive.

6. Copy all of the imagery files on the disk to the images folder located in the C:\Program Files\DugwayGIS directory.

7. When finished with the second CD repeat step 6 for any remaining imagery CDs delivered with the installation CD.

Installation of the DPG-GIS software is complete.

NOTE: You must restart your computer before the changes take place. 


\section{STARTING DPG-GIS}

1. Click the Start button on the taskbar.

2. Point to Programs to display the Programs menu.

3. Point to Dugway GIS.

4. Click Dugway GIS 2.0.

5. Click Start.
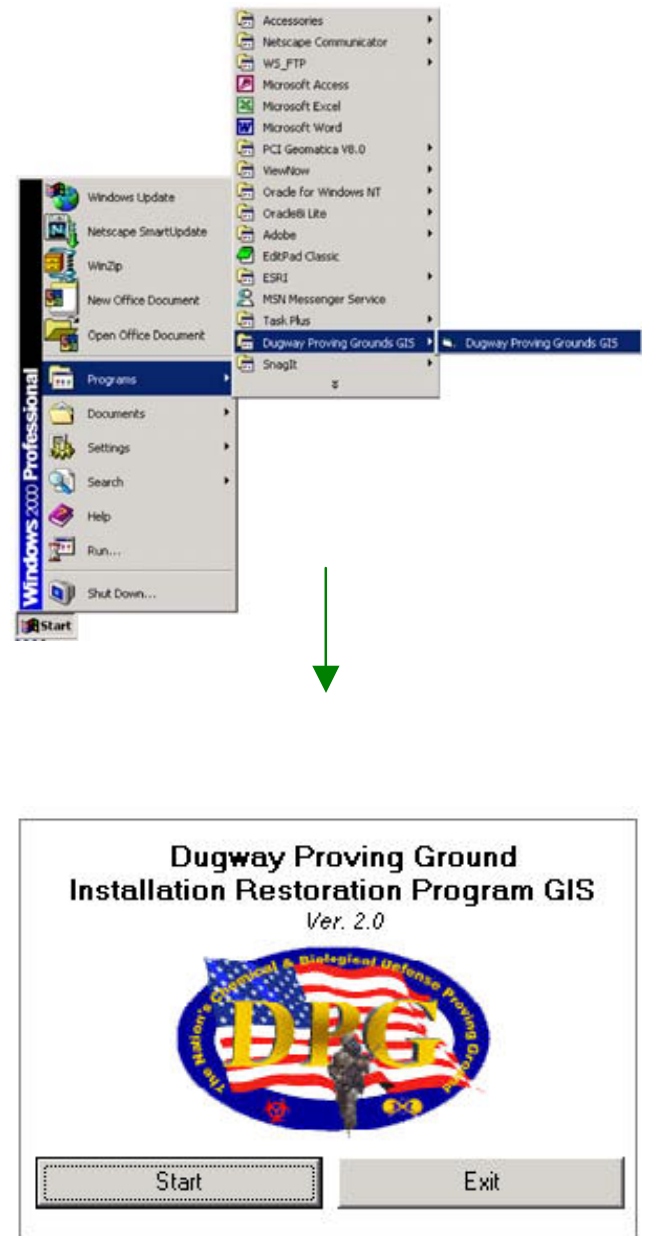

Figure 1. Startup splash screen. 


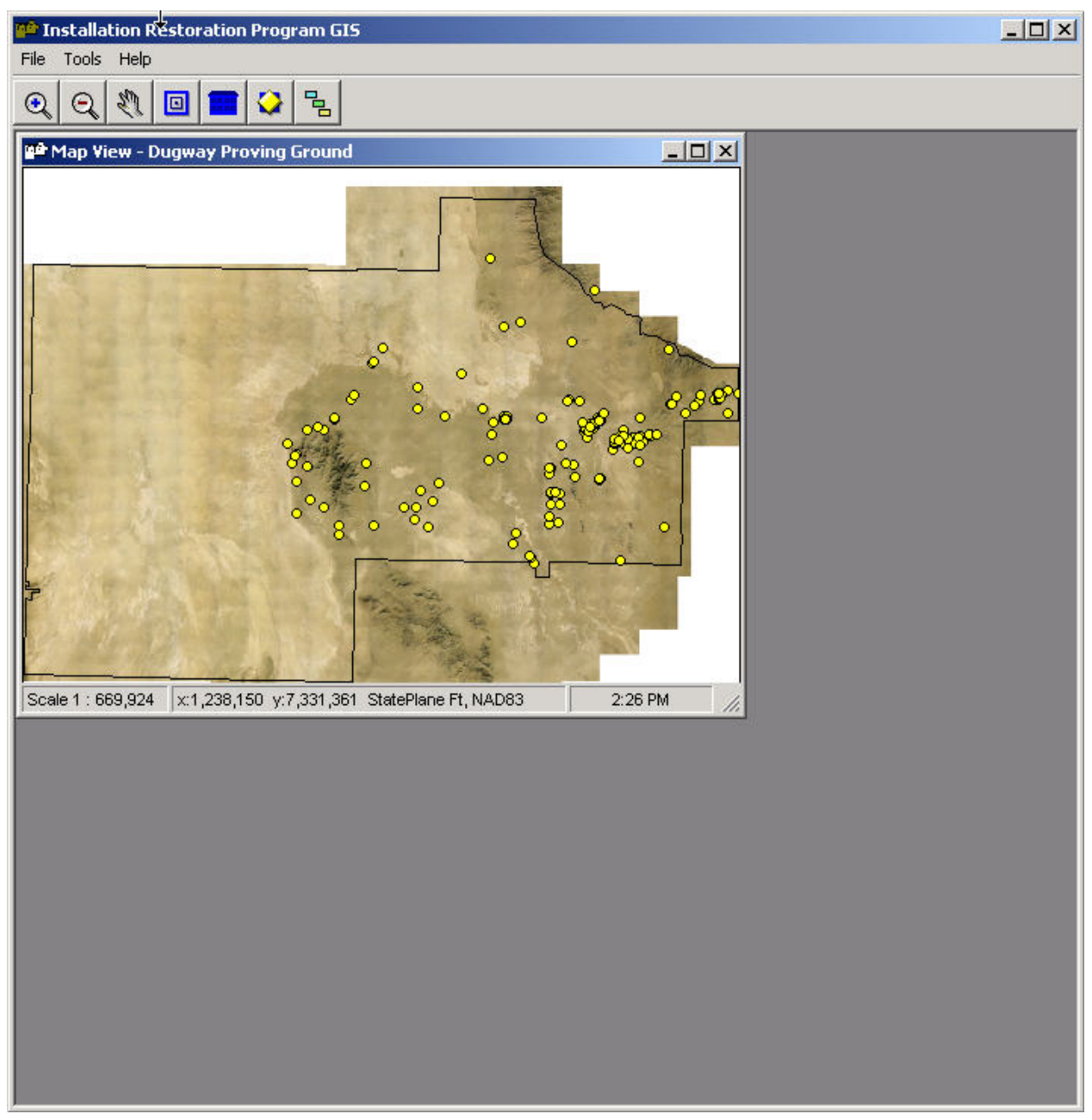

Figure 2. Map View window. This window is displayed when DPG-GIS initializes and the main application window opens. The yellow dots represent Monument locations overlaid on a high-resolution orthophoto image. Along the bottom of the map window a map scale is displayed along with geospatial data projection information and geographic coordinates location of the specific mouse location within the window. 


\section{DPG-GIS MAIN MENU AND CONTROL BUTTONS}

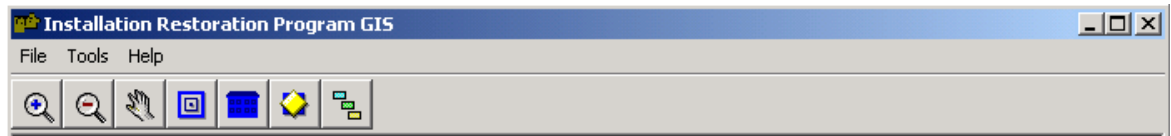

Figure 3. Main program taskbar. This taskbar includes pulldown menus and specific task-oriented icons.

$>$ In order to view the options available on the taskbar, hold the mouse pointer directly over each menu or icon for a brief description.

\section{File Menu}

Print $(\mathrm{Ctrl}+\mathrm{P})$ - Allows the user to print information directly from the screen to a locally installed printer device.

Exit-Exit the DPG-GIS program.

\section{Tools Menu}

Send Map to Clipboard-Allows the user to copy the information displayed on the Map View window and send it to the clipboard to be pasted into a Word document.

Database Query_-Opens the main Database Query window.

Layer Control-Opens the Layer Control window.

IAP Viewer-Opens the Installation Action Plan (IAP) Viewer. Also available from the Management Unit Database Query window.

Building Locator-Opens the Search by Building Interface (see Figure 11).

3D Model Viewer-Opens the 3D Model Viewer.

\section{Help Menu}

Database Interpretation-A submenu that provides specific information about database-related parameters and updates.

Submenu Headings

Analyte Groupings—Subjective analyte groupings provided by Parson's Engineering. 
UTL for Metals in Soils—Upper tolerance level for metals in Background.

Attenuation Parameters-Analytical parameters for weighting and screening.

Database Date—Date last update occurred.

About Dugway GIS—Describes the relevant software information.

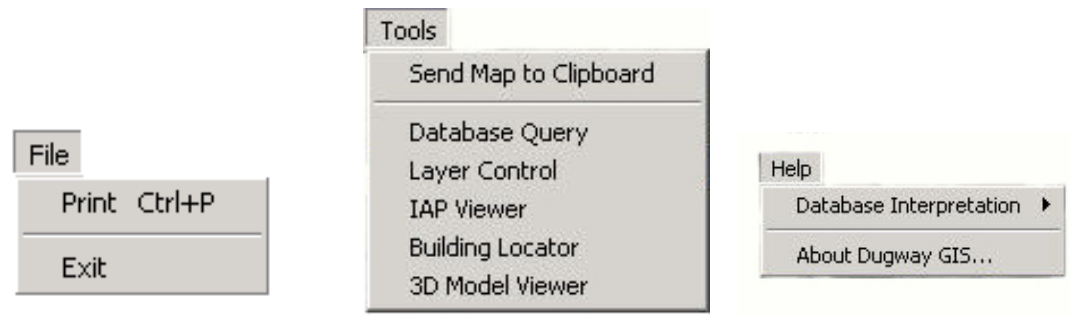

Figure 4. Pulldown menus available from the main taskbar. (See also Figure 3.)

\section{Taskbar icons}

Located directly below the file menu is a series of taskbar icons (see Figures 3 and 5). These taskbar icons perform some of the same tasks as the file menu but also provide additional functionality.

(4)

$Q$

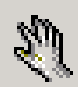

Zoom in: Zoom to a particular object in the Map View window.

Zoom out: Zoom out in the Map View window.

Pan: Reposition the Map View window to an area of interest.

Zoom to full extent: Reposition the Map View window to its full extent. 
Building Locator: Call the Building Locator Display.

Well Database Query: Call forward the Well Database Query window.

品

Layer control: Call forward the Layer Control window.

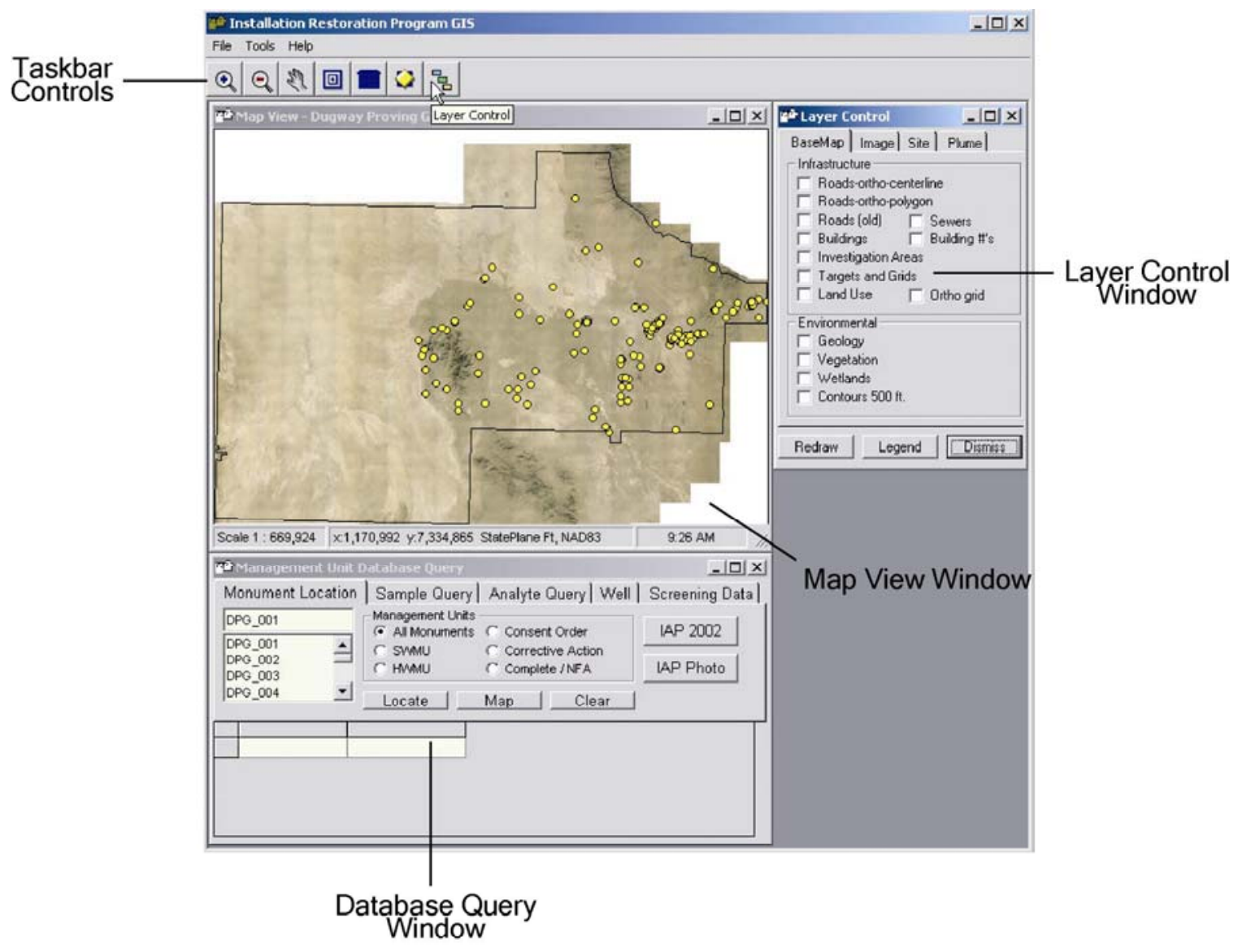

Figure 5. Overview of the DPG-GIS layout with Layer Control and Management Unit Database Query windows activated. 


\section{LAYER CONTROL WINDOW}

\section{Basemap Options}

This tab allows the user to turn on various layers of interest through the use of check boxes. These layers are exhibited as infrastructure (i.e., roads, buildings, and investigation areas) as well as environmental layers such as geology and vegetation.

\section{Image Options}

This tab allows the user to enable various layers of image data to be turned on and off. These layers are broken into three distinct sections: 1) Basewide imagery (i.e., Landsat images, Digital Raster Graphics [DRGs]), 2) Detailed SWMU site Ortho's 2002, and 3) 1998 Higgenbotham Aerial photography over specific site locations.

\section{Site Options}

This tab allows the user to enable layers that are specific to each particular monument location. These layers include line and polygon features as well as detailed road layers.

\section{Plume Options}

This tab allows the user to enable various contamination concentrations that may be available for a particular monument location. 


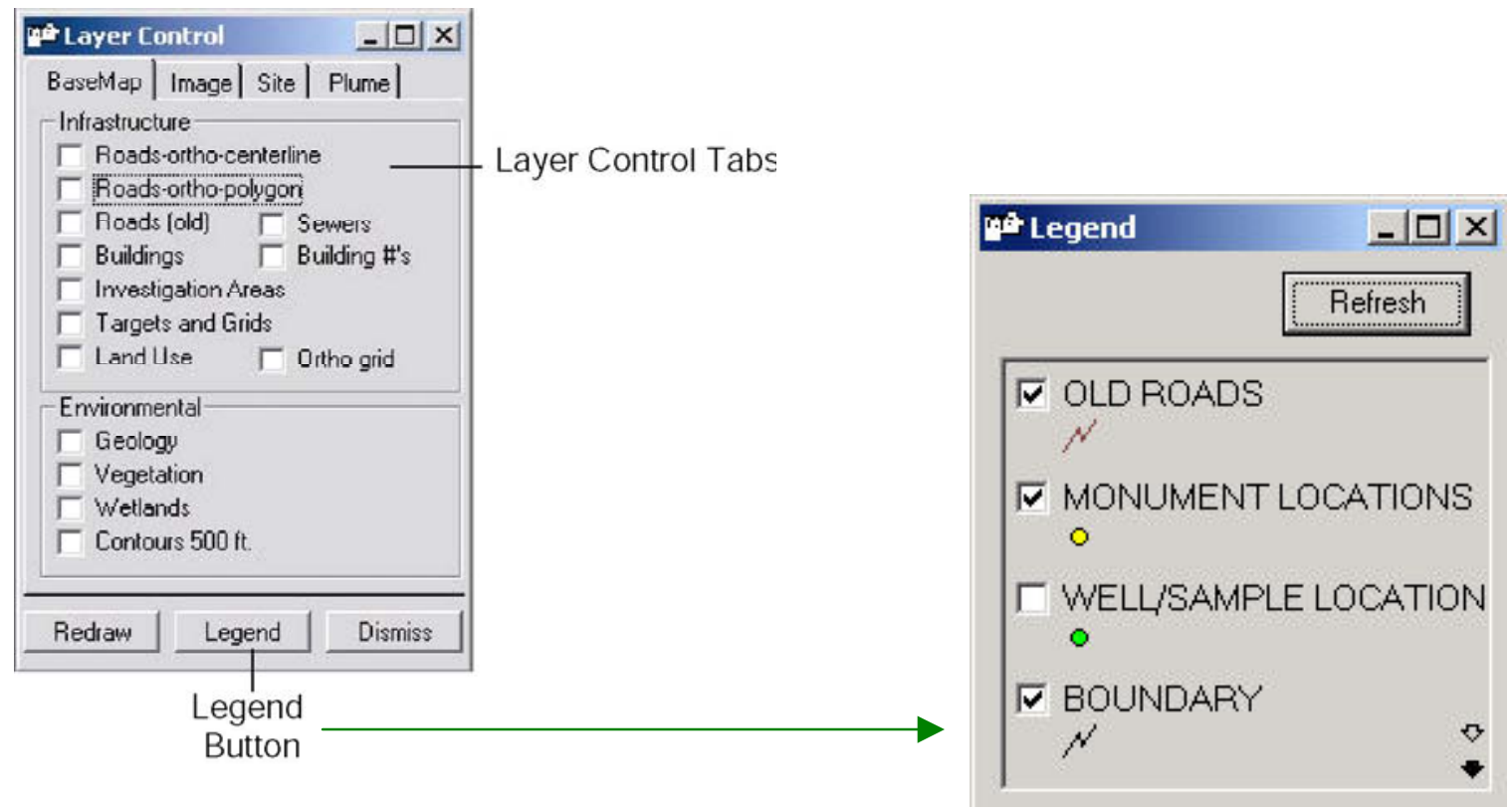

Figure 6. Layer Control and Legend windows. 


\section{MANAGEMENT UNIT DATABASE QUERY WINDOW}

The Management Unit Database Query window allows the user to extract specific information for particular monument locations, sample types, analytes, and specific well information.

\section{Monument Location tab}

The Monument Location tab builds information in the Map View window according to user-defined selections about particular monument sites.

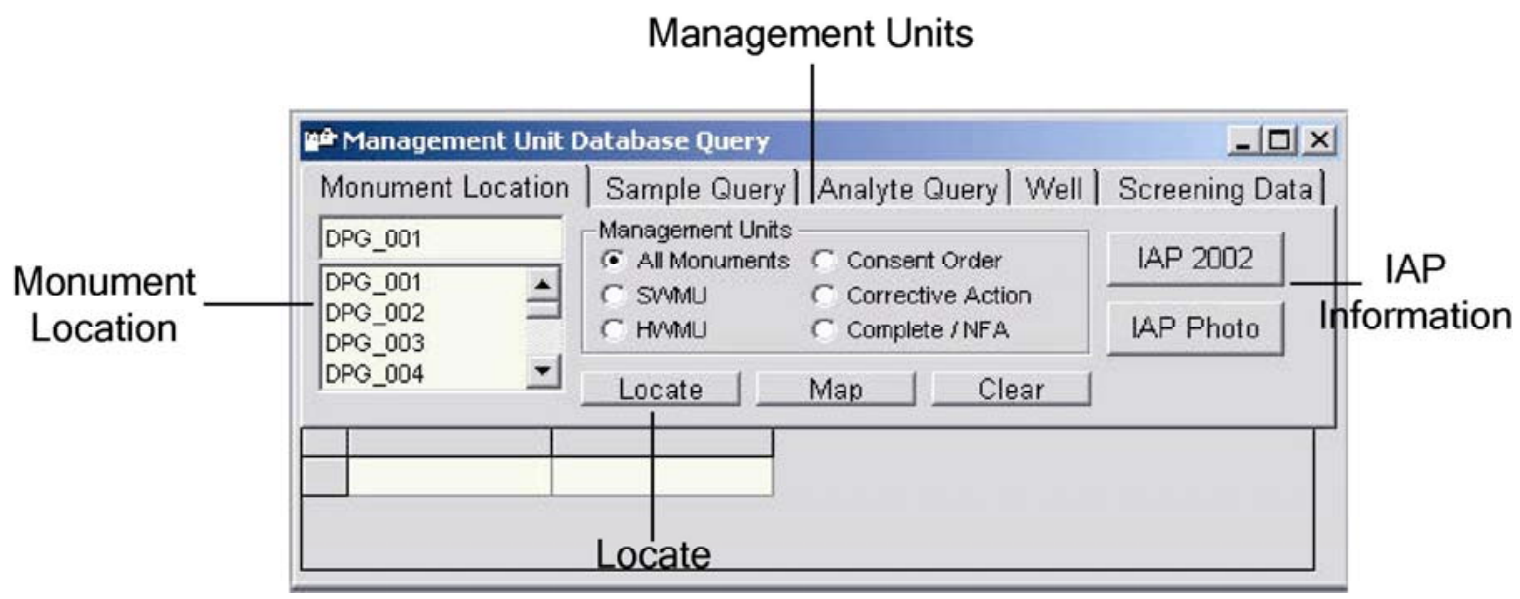

Figure 7. Monument Location tab overview.

Management Units (radio buttons)

The Management Unit section allows the user to narrow the type of monument location search by specific criteria. These criteria are All Monuments, SWMU, HWMU, Consent Order, Corrective Action, and Complete/NFA.

Locate (button)

By highlighting the monument location of interest and depressing the Locate button, the Map View window shows a zoomed-in view of the Monument site (yellow dots) along with the corresponding well locations (green dots) associated with the locality. 
IAP Information (buttons)

IAP Information for a selected monument site can be displayed by depressing one of the IAP buttons along the left side of the dialog box. By depressing the IAP 2002 button the IAP viewer is displayed along with any IAP information for the given monument location. By depressing the IAP Photo button all available photographs for the location are displayed.

\section{Sample Query tab}

The Sample Query tab allows the user to obtain detailed geographic and chemical information about a particular well located at a chosen monument site.

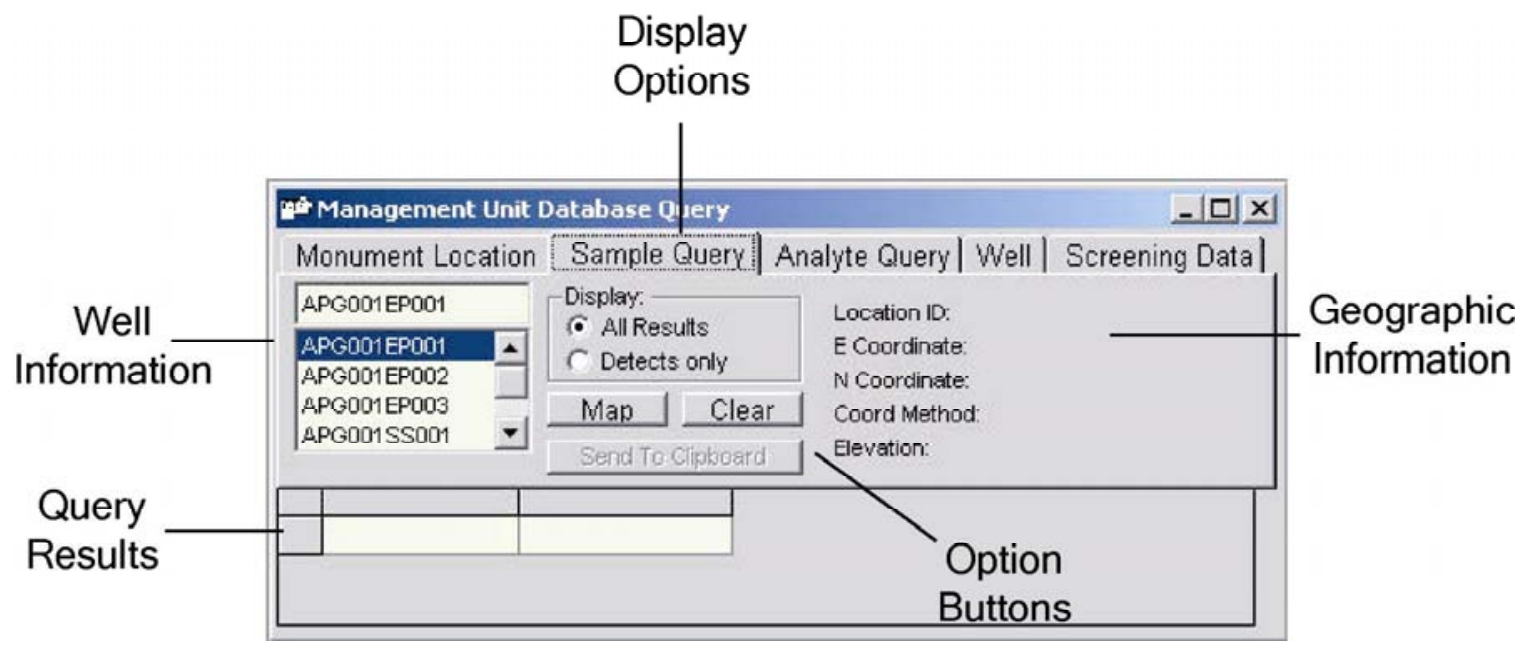

Figure 8. Sample Query tab overview.

Well Information

The Well Information window displays the well identification numbers (LOCID) that are associated with a chosen monument location.

\section{Display Options (radio buttons)}

The Display Options let the user query all information acquired for a particular well or only where there has been information detected about a particular analyte. 


\section{Query Results}

This window displays the query results for each individual well that has been selected for a particular monument.

\section{Geographic Information}

The geographic information such as Coordinates, Location ID, and Elevation are displayed about a particular well.

\section{Option Buttons}

Certain options can be selected here, e.g., the Map button, which highlights the well of interest in the Map View window or sends the query results to the clipboard to be pasted into a spreadsheet.

\section{Analyte Query tab}

The Analyte Query tab allows the user to search for locations based on a particular or set of analytes, matrix, type, and detection level.

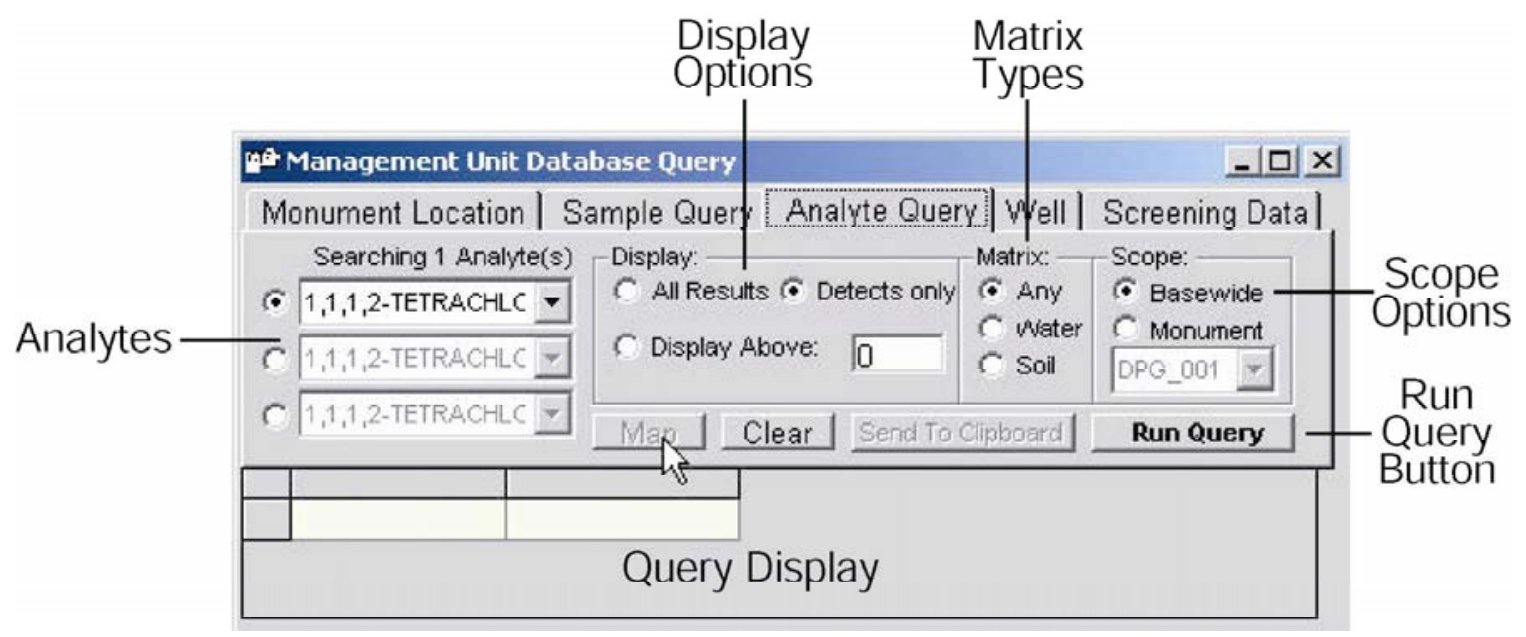

Figure 9. Analyte Query tab overview.

Analytes

The Analytes selection box allows the user to select up to three analytes to search for through the use of pulldown menus and radio buttons. 


\section{Display Options}

The Display Options section allows the user to select the type of analyte results of interest to the user. These include all results, detects only, and a userdefined detection level above which the results will be displayed.

\section{Matrix Types}

The Matrix Type section allows the user to further narrow the query results by narrowing the type of sampling matrix. The options are any, water, and soil.

\section{Scope Options}

The Scope Options section allows the user to select data from the entire base or to narrow the results to a particular monument location.

\section{Run Query Button}

Activates the users query.

\section{Well Information tab}

The Well Information tab enables a search for any additional well information that may reside in the database regarding monitoring wells.

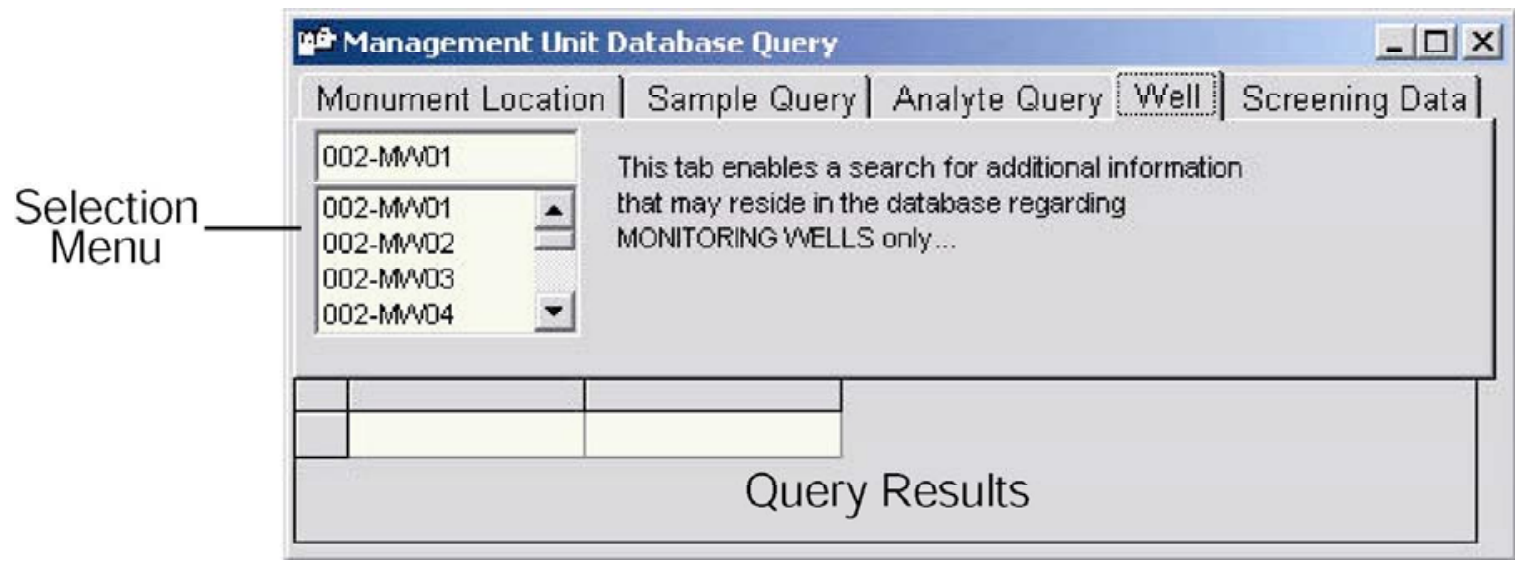

Figure 10. Well Information tab overview. 


\section{Selection Menu}

The Selection Menu houses all the monitoring well numbers. By selecting a particular monitoring well from the pulldown menu, the results for that particular well will be displayed in the Query Results window.

\section{Screening Data tab}

The Screening Data tab enables a search for information related directly to screening data such as soil gas, hydropunch, and TNT. These data are not considered definitive-level data.

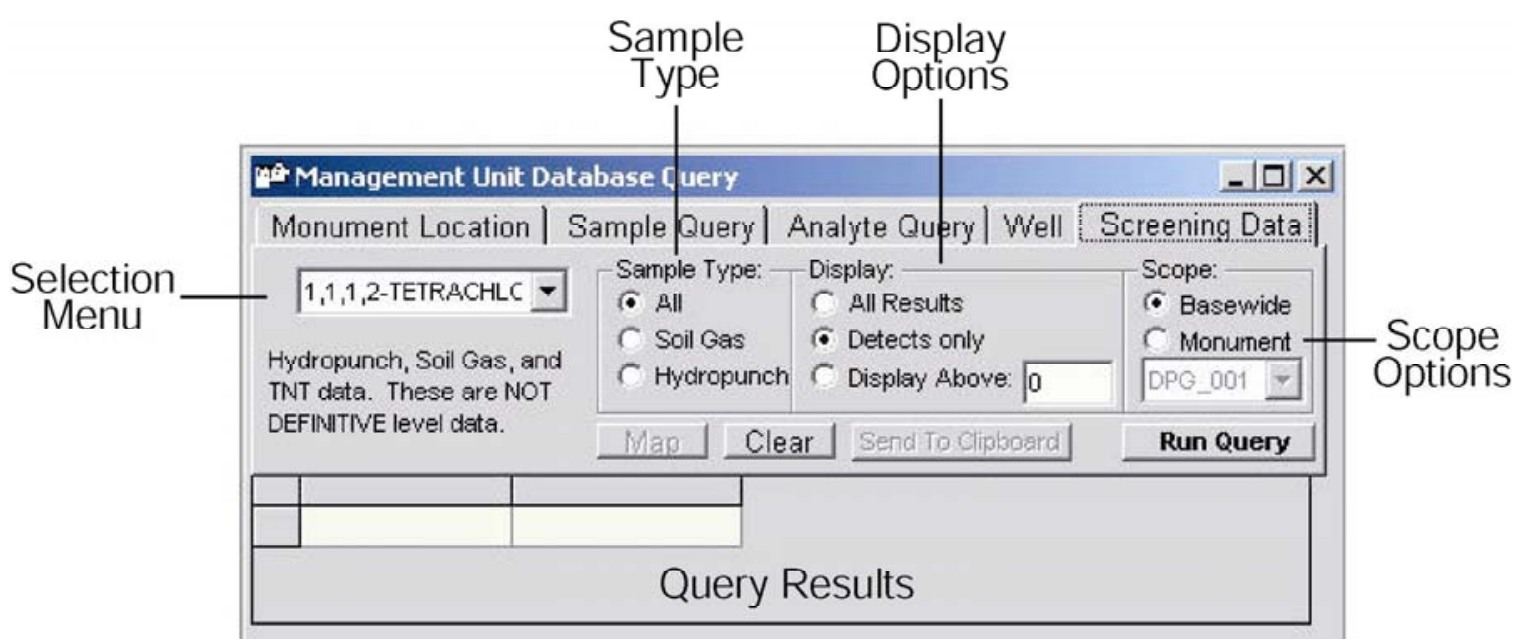

\section{Selection Menu}

The Analyte Selection box allows the user to select an analyte to search for using the pulldown menu.

\section{Sample Type}

The Sample Type section allows the user to further narrow the query results by narrowing the type of sample. The options are soil gas, hydropunch, and all.

\section{Display Options}

The Display Options section allows the user to select the type of analyte results the user is interested in displaying. These include all results, detects only, and a user-defined detection level above which the results will be displayed. 


\section{Scope Options}

The Scope Options section allows the user to select data from the entire base or to narrow the results to a particular monument location (SWMU or HWMU). 


\section{BUILDING LOCATOR WINDOW}

\section{Locate Building}

The Locate Building dialog box is located under the Tools pulldown menu from the taskbar and toolbar. This option allows the user to zoom to a particular building in the Map View window by selecting a building number of the user's interest. (NOTE: The buildings option must be selected in the basemap layers control menu in order to operate correctly.)

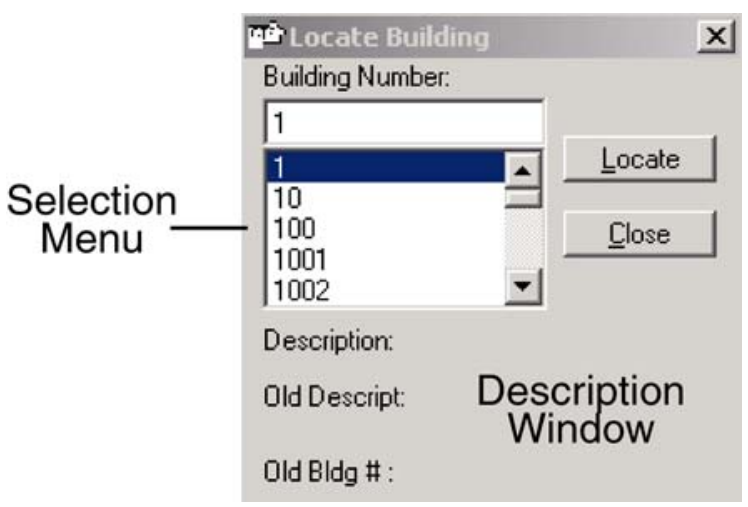

Figure 11. Building Locator window. 


\section{APPENDIX A. EXERCISES AND EXAMPLES}

\section{EXERCISE 1}

\section{Viewing a Specific Monument Location}

For this and the remaining exercises, unless noted otherwise, Monument Location DPG_003 will be used.

1. In the Monument Location tab of the query dialog box, check the management unit type desired (i.e., SWMU, HWMU, Corrective, etc.). Use SWMU for this exercise.

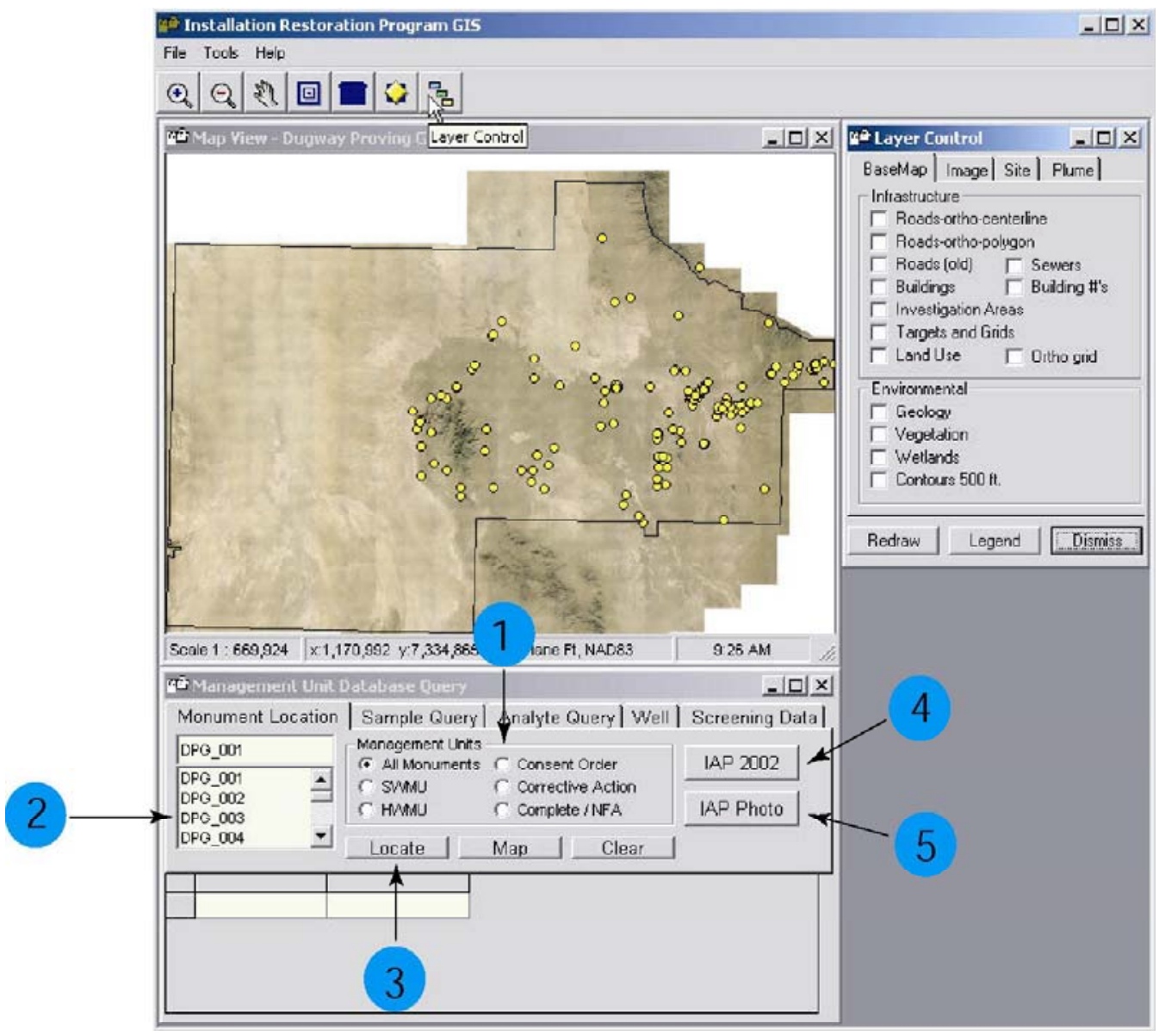

2. Select the Monument Location of interest (DPG_003). 
3. Click the Locate button.

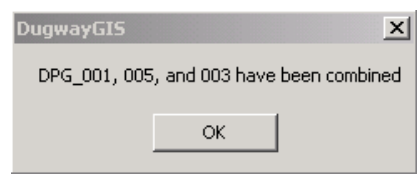

After clicking the Locate button, if the Monument Location you have chosen has recently been combined with any other Monument Locations as defined by the most recent IAP, a warning screen will inform you which locations have been combined.
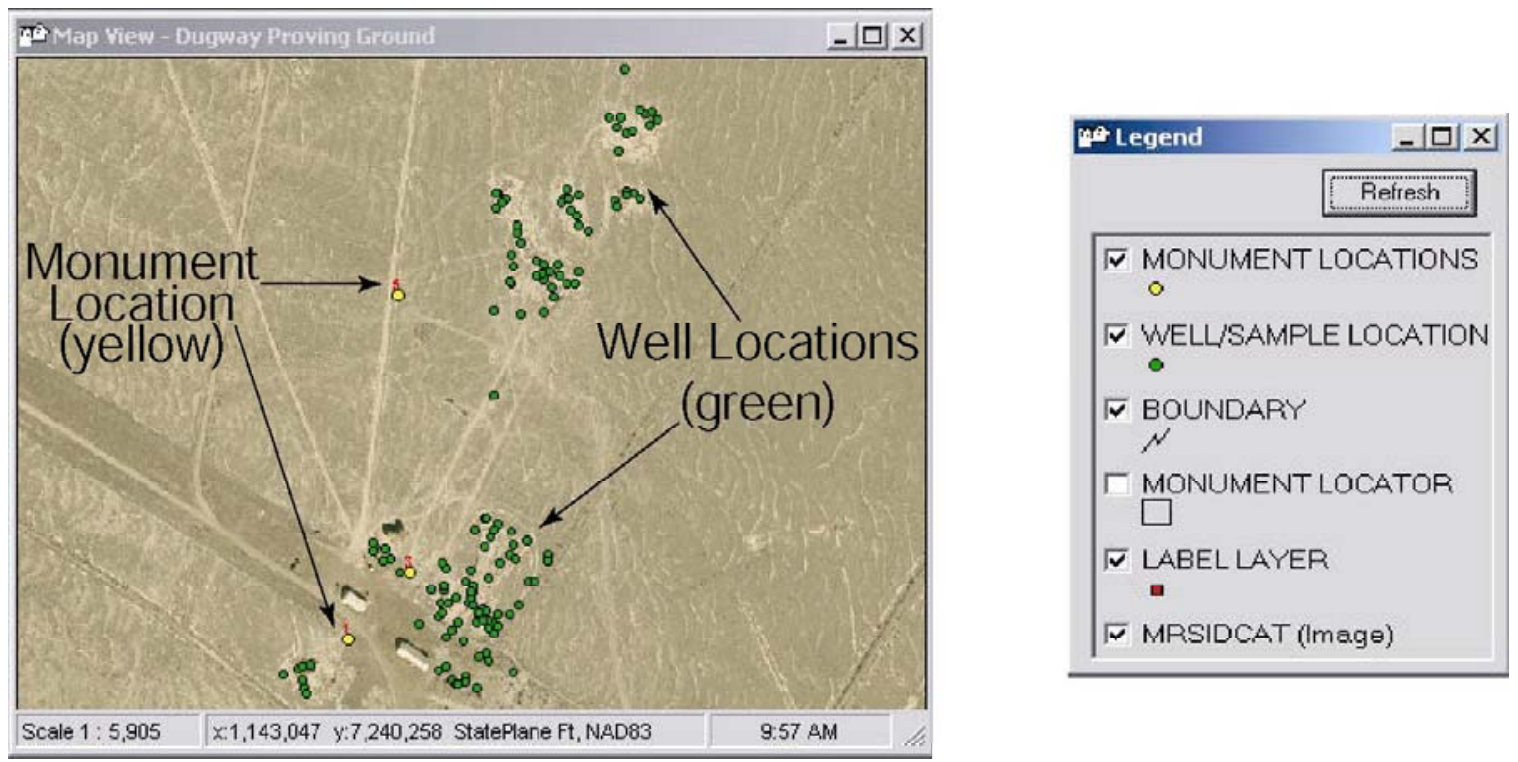

The Map View window changes to show you the desired monument location (yellow) at a more appropriate scale. Included in the Map View window are all monitoring well locations (green). Other layer options can be toggled on or off from the Layers window, including the removal of the background image and the Legend window (right).

NOTE: Layers cannot be toggled on or off from the Legend window. Use the Refresh button on the Legend window to update the legend as layers are added and removed.

The Monument Location tab is also used to view the Installation Action Plan (IAP) information for particular Monument Locations. 
4. Click the IAP 2002 button to view the available photos associated with the Monument Location and the IAP.

5. Click the IAP Photo button.

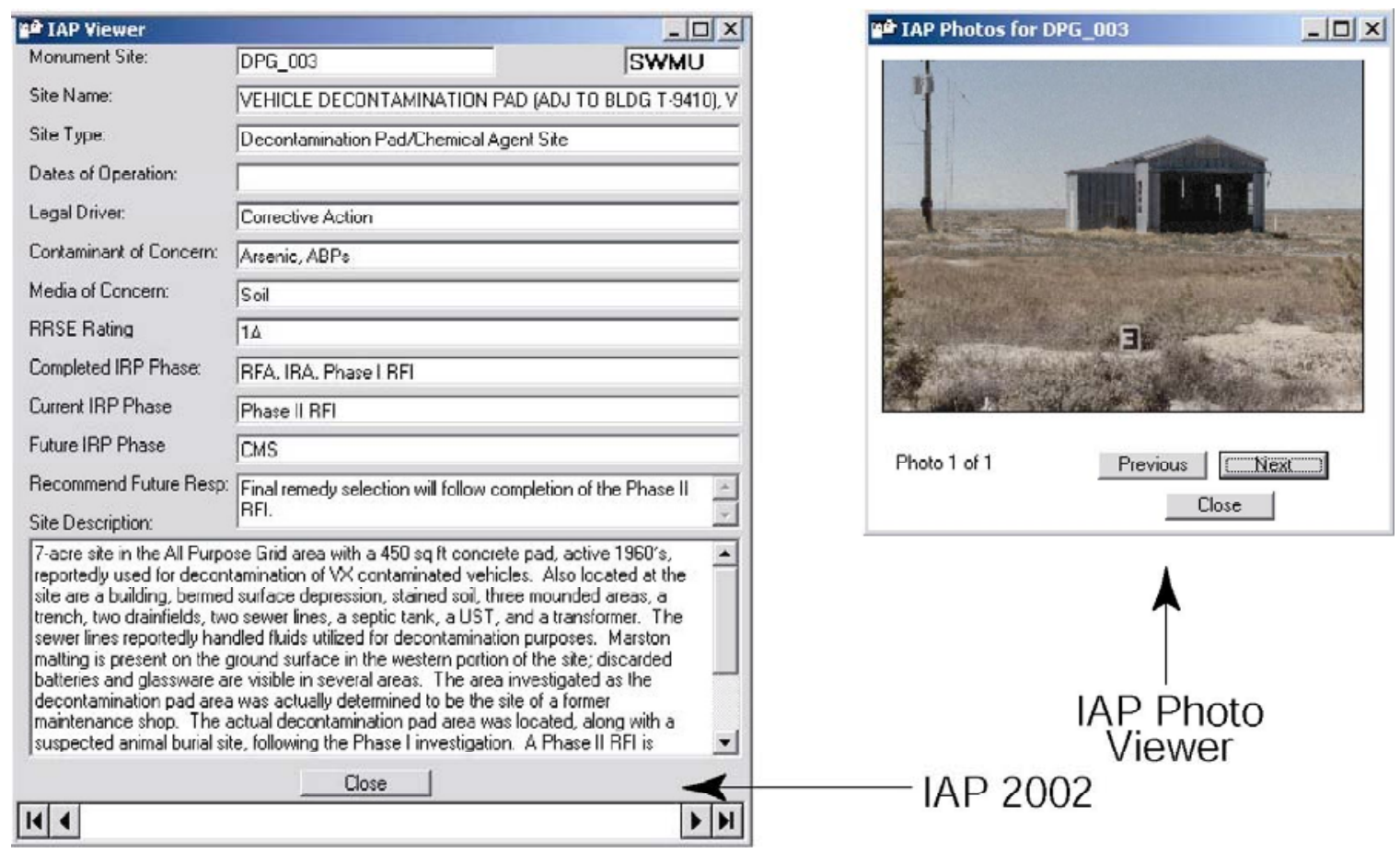

\section{EXERCISE 2}

\section{Performing a sample query}

Select Monument Location DPG_003 using the same steps outlined in Exercise 1.

1. Activate the Sample Query tab.

2. Check the appropriate display checkbox: All Results or Detects Only. For this exercise, check the box next to Detects Only (i.e., only chemicals that have been detected will be displayed in the Query window). 


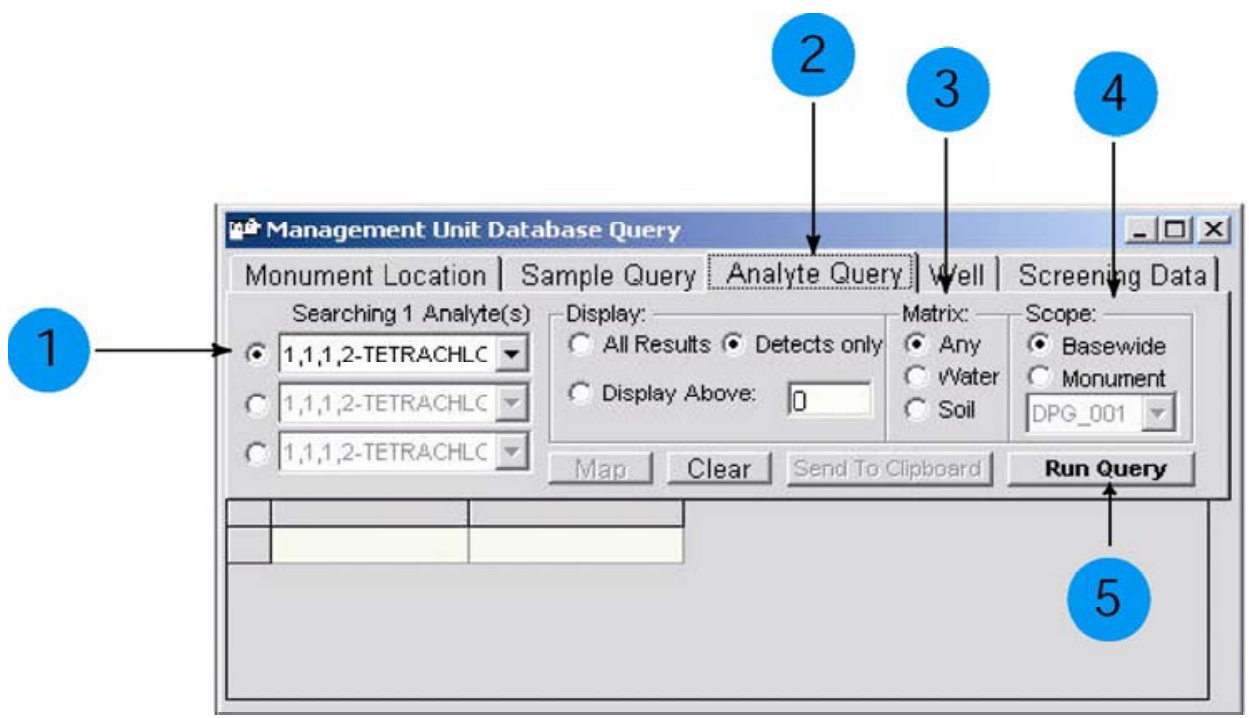

3. Choose a well of interest from the left-hand pulldown menu of LOCIDs (use APG003EP006). A specific LOCID for a particular well can be determined by dragging the mouse cursor over a green well location in the Map View window. The LOCID will then be displayed on screen.

Immediately following step 3 the query is activated and the results are displayed at the bottom in the Query Display window. Geospatial information regarding the well location is displayed along the right-hand side of the window while the number of detection results are given directly above the Query Results window.

4. Click the Map button. The well location in the Map View window that corresponds to the LOCID in the left-hand column will flash and turn from green to red. (NOTE: To remove the highlighted well location from red back to green in the Map View window, depress the Clear button on the Display Options panel.) 


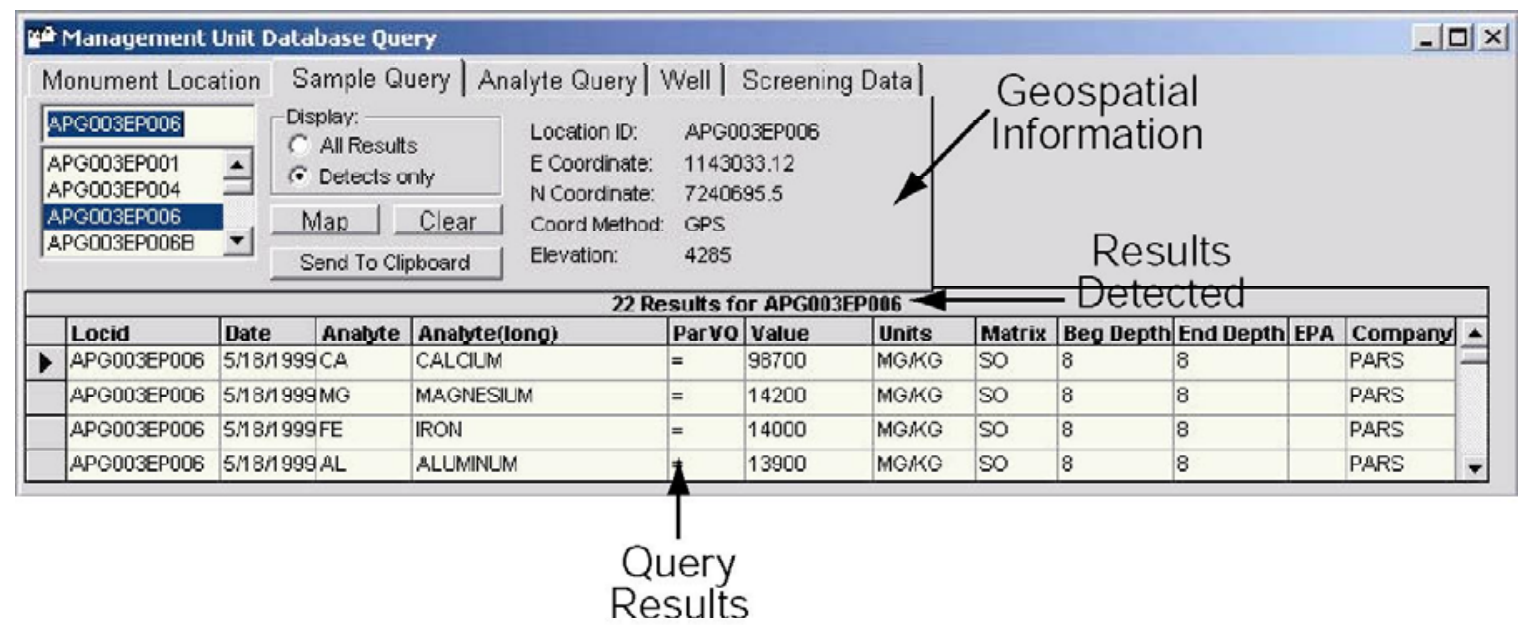

Querying a well location from the Map View window

It is also possible to query information about a specific well location by selecting it from the Map View window.

Follow the instructions outlined in Exercise 1 for selecting a Monument Location.

1. Depress the Well Database button on the toolbar.

2. Make sure the Sample Query tab is active.

3. Use the mouse cursor to select a green well sample location from the Map View window. 


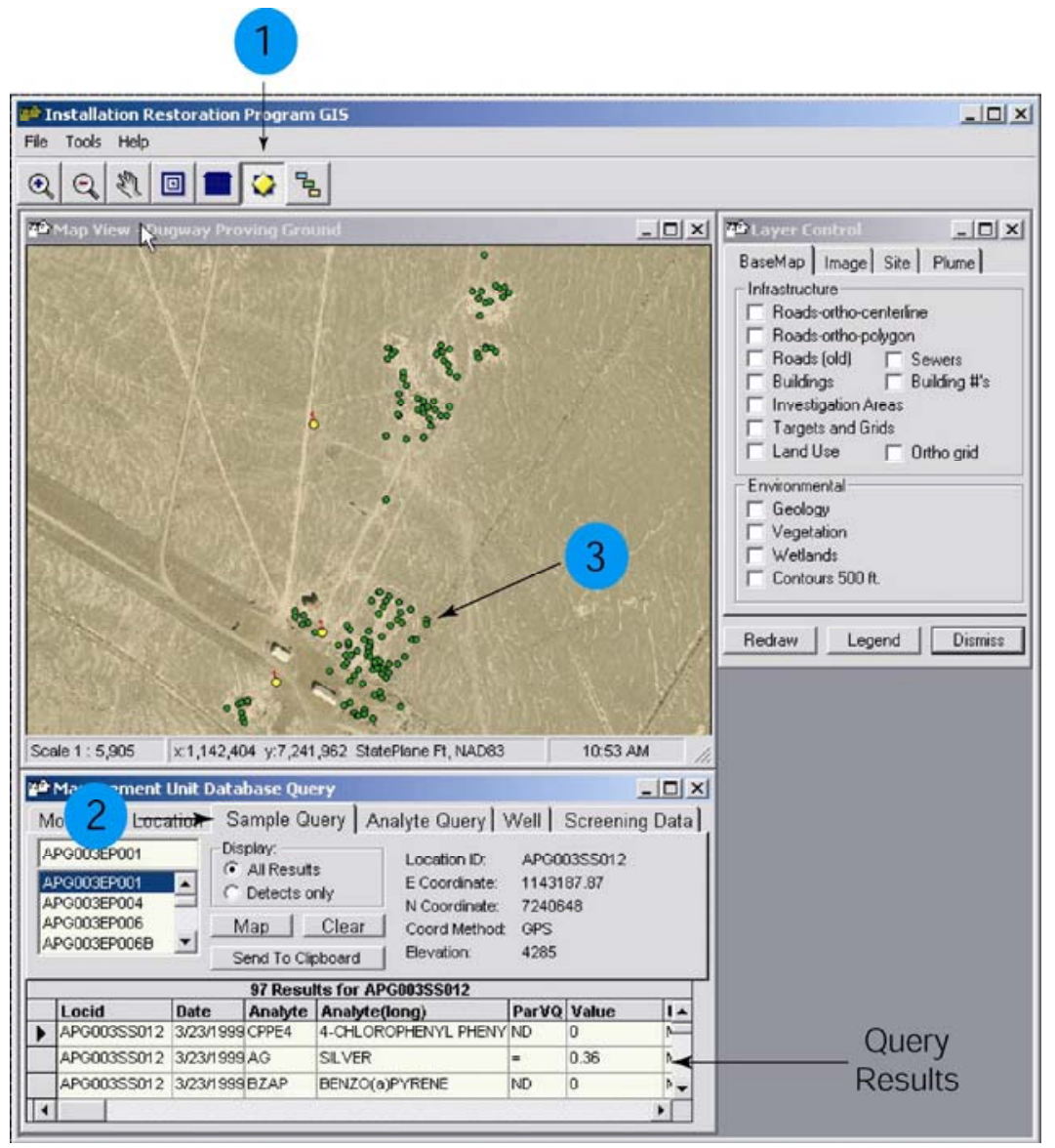

Once the well location has been selected from the Map View window, the results are automatically transferred to the Query Results window.

How to save your query results to a report format

In order to save the results from this and other queries to a report format, you will need to follow the steps outlined below.

1. Depress the Send to Clipboard button. (Once the Clipboard button has been depressed, the query results have been copied to the clipboard so they can be pasted into a spreadsheet document.)

2. Open a spreadsheet utility (e.g., Microsoft Excel).

3. Navigate to the Edit menu in Excel and click on Paste. 


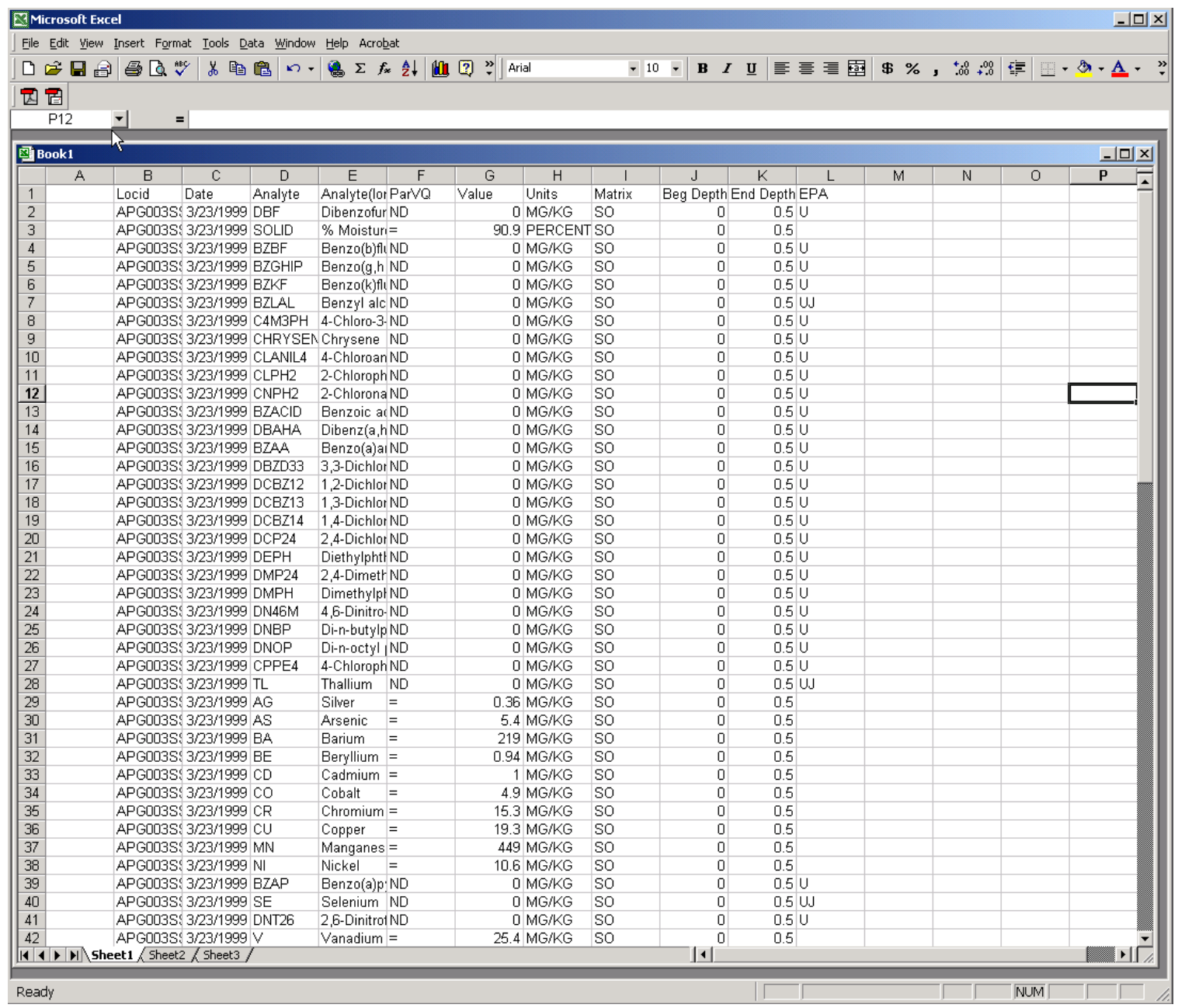

Once you have followed these steps, your results should look like the image above, with each column being separate. While similar results are achieved when using a document reader such as Microsoft Word, this method results in a tabdelimited format. Therefore, it is much easier to use Microsoft Excel to table the data and then insert the resulting table into your Word document.

\section{EXERCISE 3}

\section{Executing an analyte query}

An analyte query allows the user to search the entire monument location database for a particular type of analyte or combinations of up to three different 
analytes. The results provide the user with the LOCID, date, and other relevant chemical testing information for each site.

1. Select the Analyte Query tab, click the checkbox to the left of the pulldown menu, and choose the STRONTIUM analyte from the scrolling list of analytes.

2. In the Display section, choose the type of results you want to be displayed.

All results: Display all types of results, regardless of the testing outcome.

Detects only: Display only results where detection for a particular analyte has been achieved.

Display above: A user-defined "base” value, which then displays results only above the entered value.

For this exercise, check the Detects Only box.

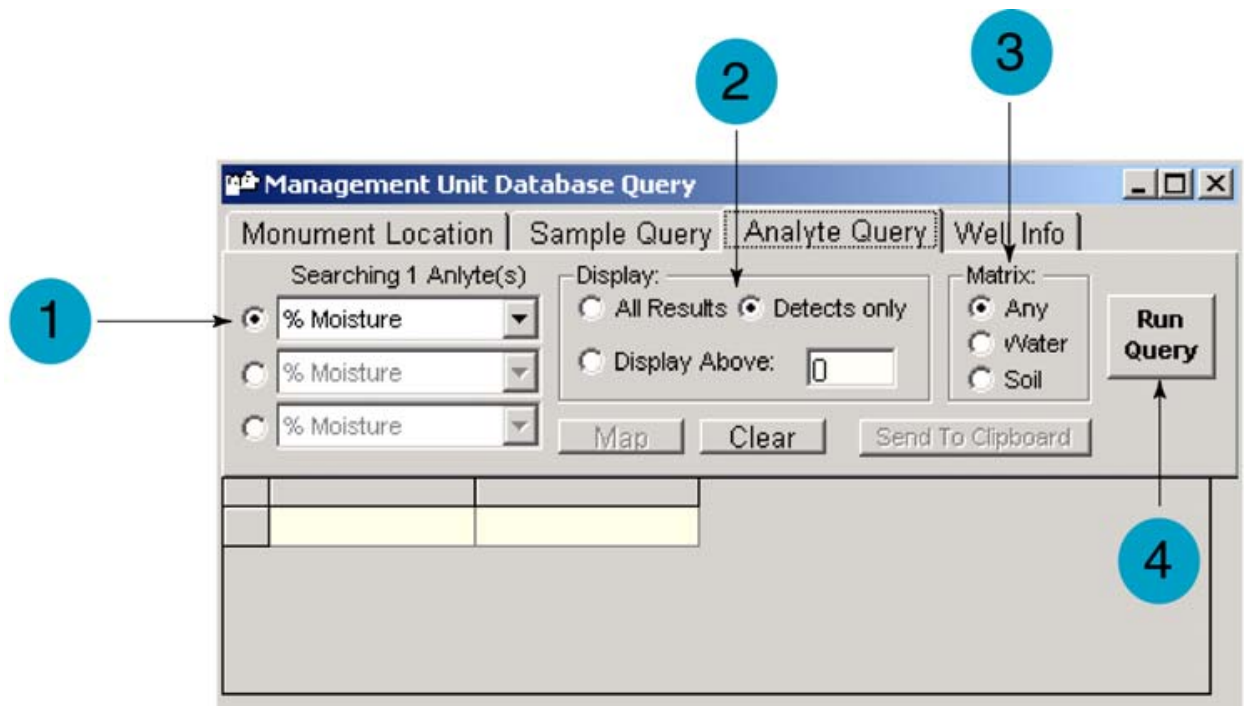

3. Choose the matrix type desired under the matrix section:

Any: All types of matrix.

Water: Water-only matrix.

Soil: Soil-only matrix.

$>$ For this exercise, check the Any box.

4. Choose the area of the search in the scope section: 
Basewide: Search all locations at DPG.

Monument: Search a particular monument location.

$>$ For this exercise, check the Basewide box.

5. Click the Run Query button.

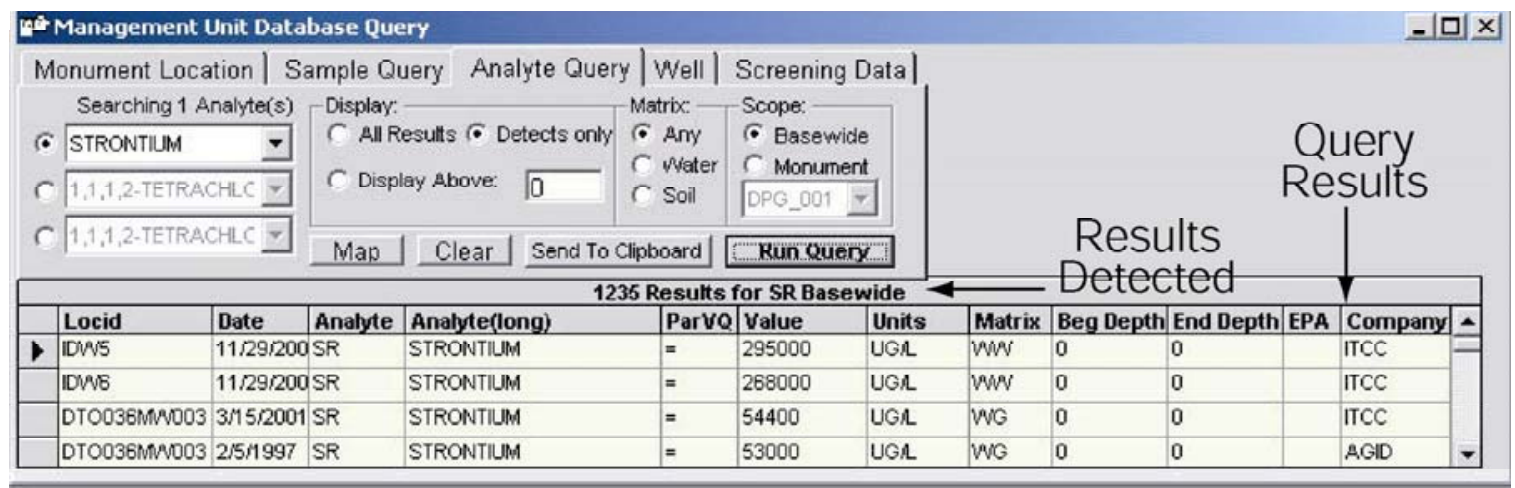

After completing step 5 and executing the query, the information retrieved from the database is displayed in the Query Results window. The number of results for the queried analyte is displayed directly above the Query Results window.

\section{EXERCISE 4}

\section{Executing a Multiple/Threshold Analyte Query}

This exercise illustrates how the user can perform a query for up to three different analytes using the Analyte Query tab. Furthermore, it also instructs users how to refine their results by defining a threshold.

1. Click the top radio button to the left of the pulldown menu and choose the DINOSEB analyte from the scrolling pulldown list of analytes.

2. Click the second analyte radio button and select 1,1-Dichloroethene from the scrolling analyte list.

3. Click the third analyte radio button and select 1,1,1,2-Tetrachloroethane from the scrolling analyte list. 


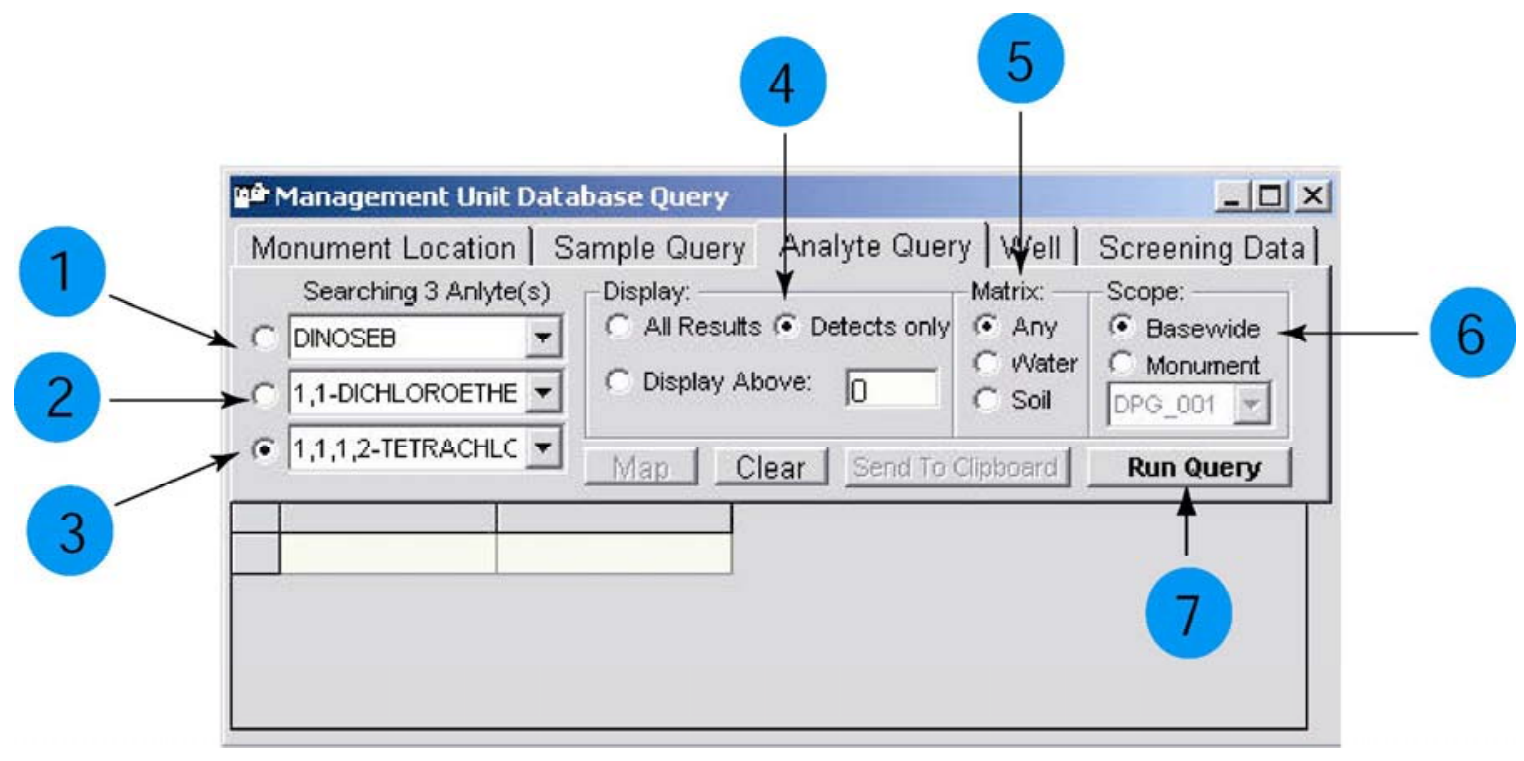

4. In the Display section, choose the Detects Only button.

5. Choose the matrix type desired under the matrix section.

Check Any for this exercise.

6. Choose the area of the search in the Scope section:

Basewide: Search all locations at DPG.

Monument: Search a particular monument location.

$>$ For this exercise, check the Basewide box.

7. Click the Run Query button.

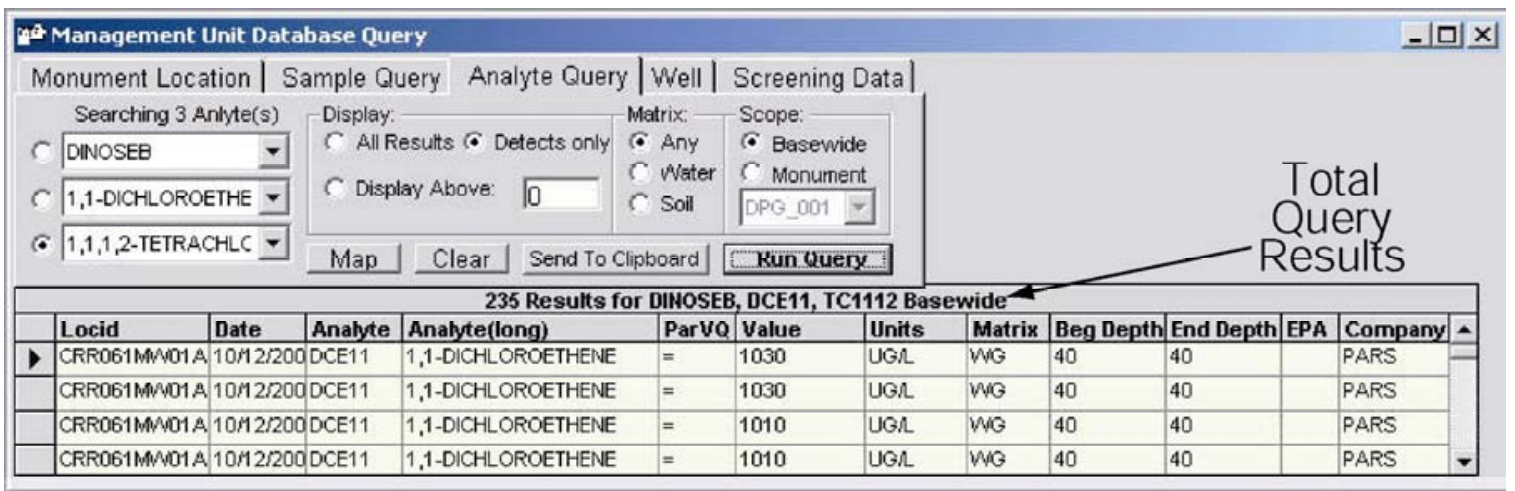


After completing step 7 the query results for all three chemicals are displayed in the Query Results window with the total number of analytes detected (235 results).

To further refine the results of your query the Display Above option can be used to define a base threshold value for detection results.

In this example, we would like to display only the results that are above a detection value of 1000 .

1. Click the Display Above button in Display options.

2. Enter a value of 1000 .

3. Click the Run Query button.

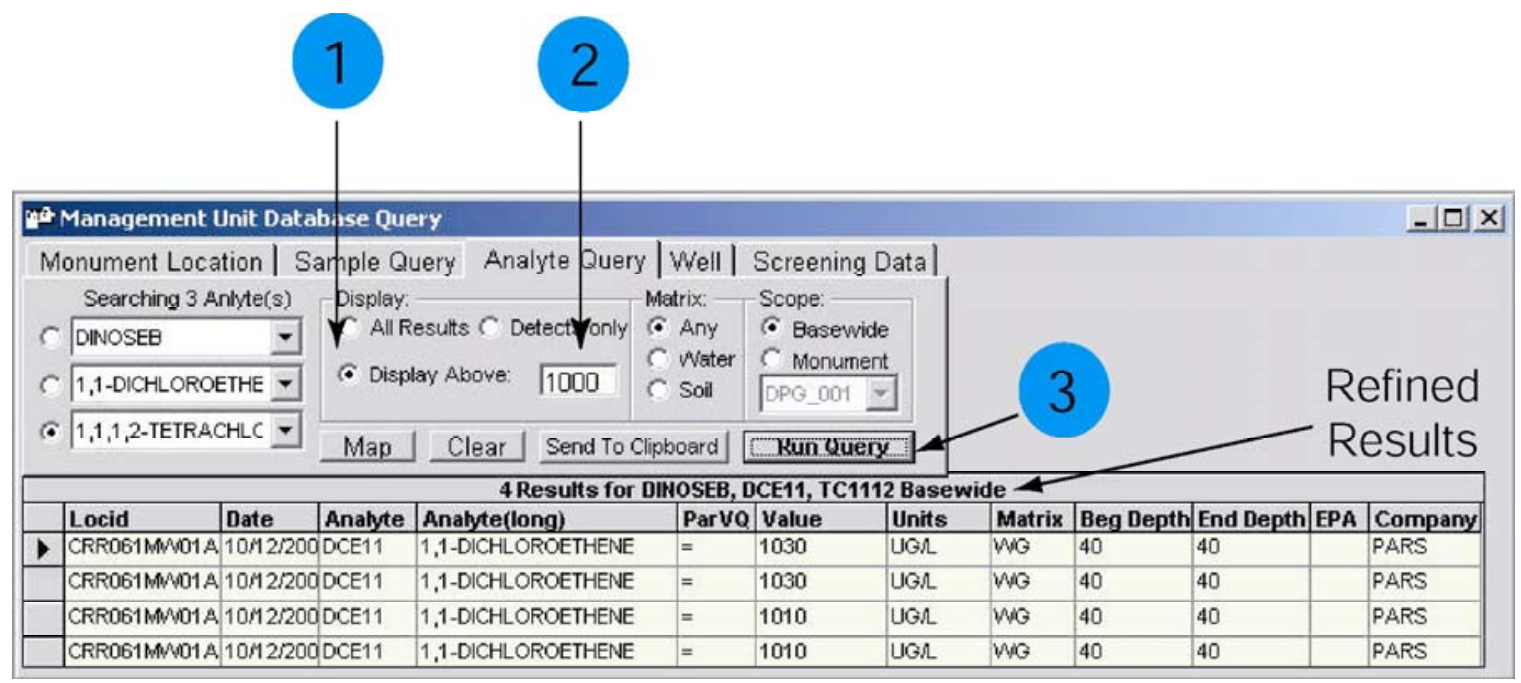

The results of using the Display Above option are displayed in the Query Results window. The number of query results is significantly reduced from an initial 235 to a more refined number of four.

Displaying query results as locations in the Map View window

It's possible to display the location of the query results in the Map View window by utilizing the Map button.

1. Make sure the Map View window is at full extent by depressing the Zoom to Full Extent button on the toolbar. 
2. Click the Clear button in the Query window to make sure any previous map results are removed from the Map View window.

3. Click the Map button.

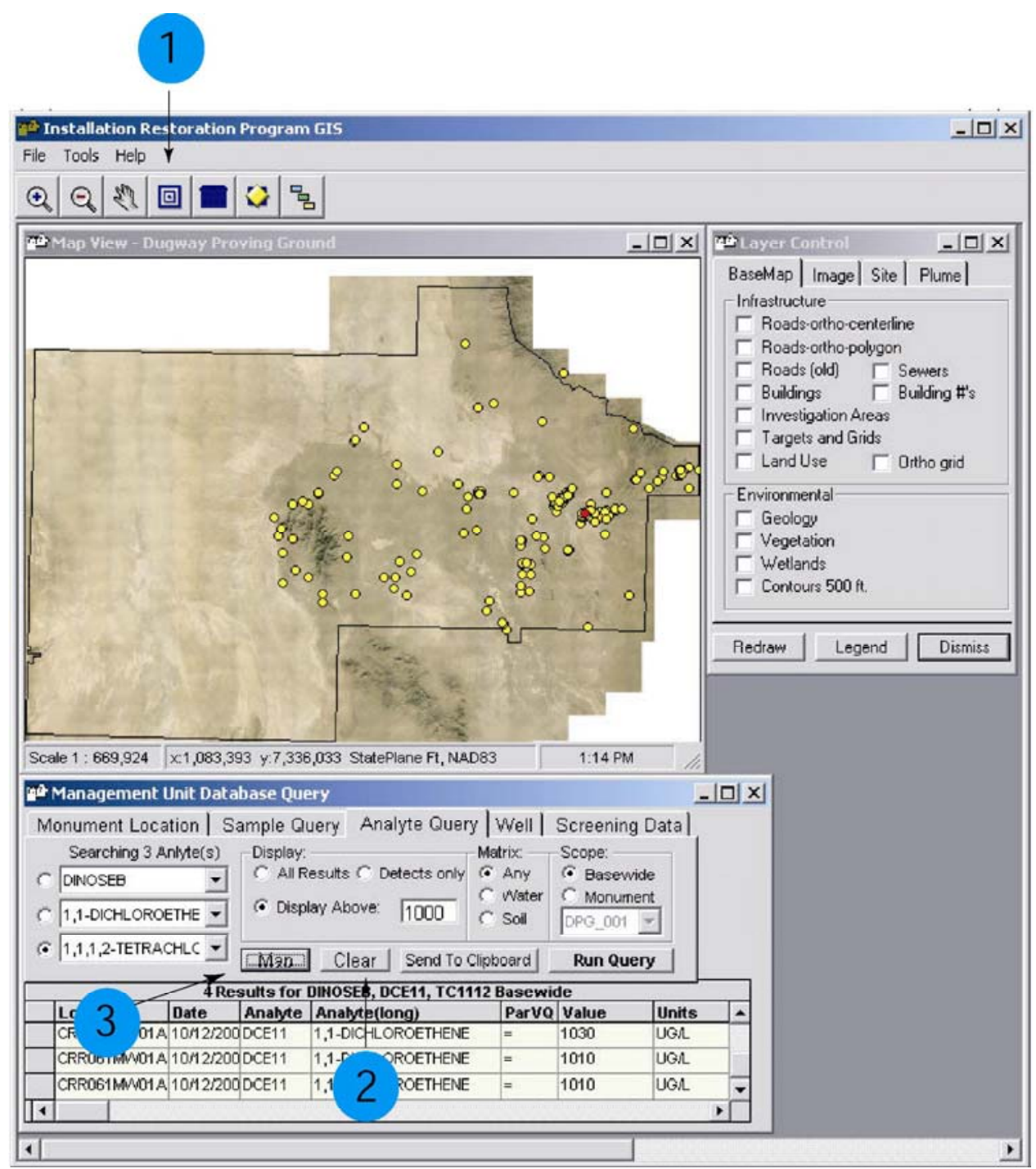

The results of using the Map button will display the queried sample locations in red across the Map View window. Zoom into a red sample location result to see this more clearly. 


\section{EXERCISE 5}

\section{Adjusting layers and copying the Map View window for printing}

1. From the Monument Location tab, select the DPG_079 monument location.

2. Click the Locate button.

3. From the Layers window select the Image tab and check the SWMU 79 checkbox from the detailed SWMU ortho's 2001 section.

4. Click the Legend button. (If the Legend box is open, click the Refresh button.)

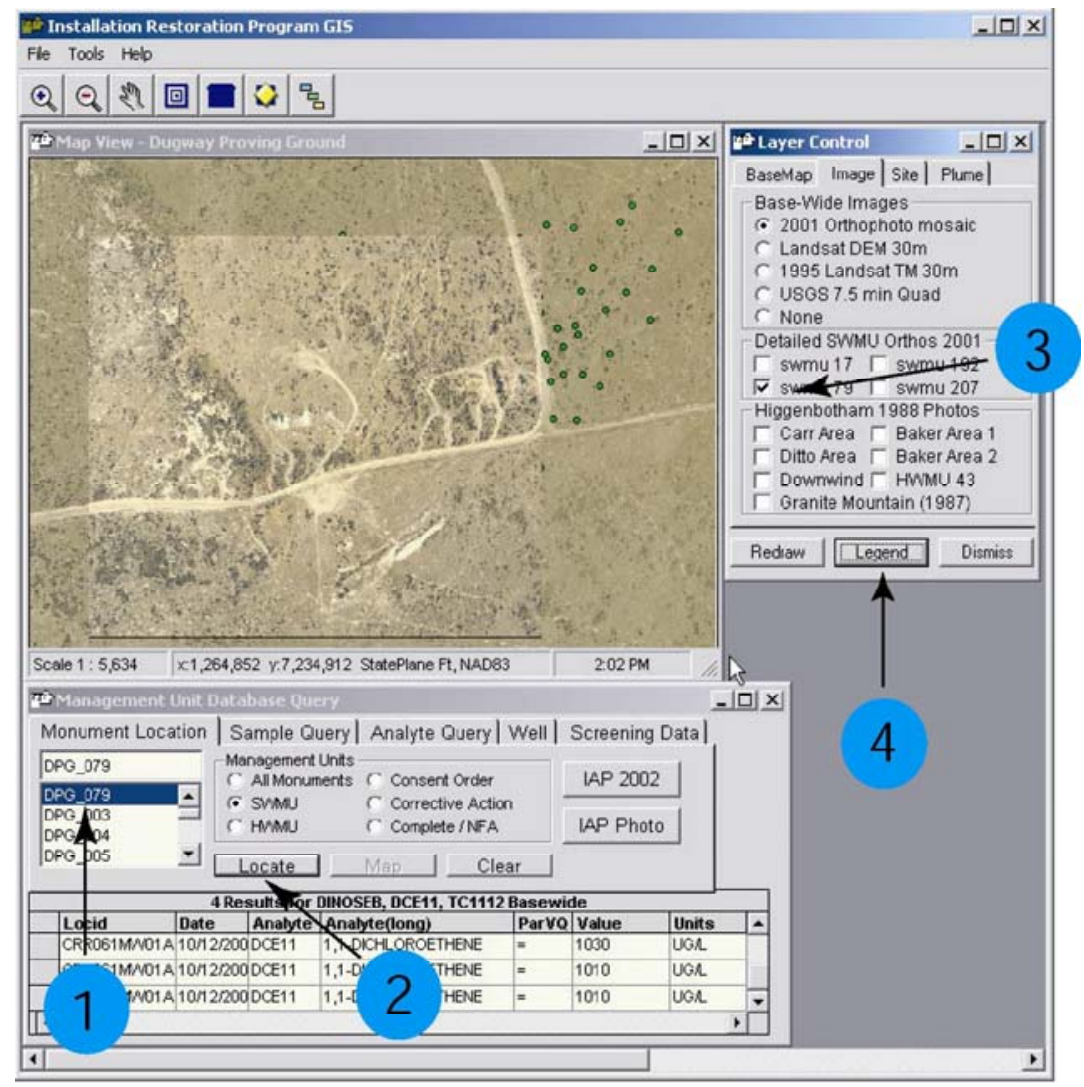

Once you have followed steps 1 through 4 a zoomed-in image of DPG_079 should be seen in the Map View window. Although the monument and well locations have been covered by the ortho photography image, this problem is easily fixed by using the Legend window to adjust the positioning of the layers. 


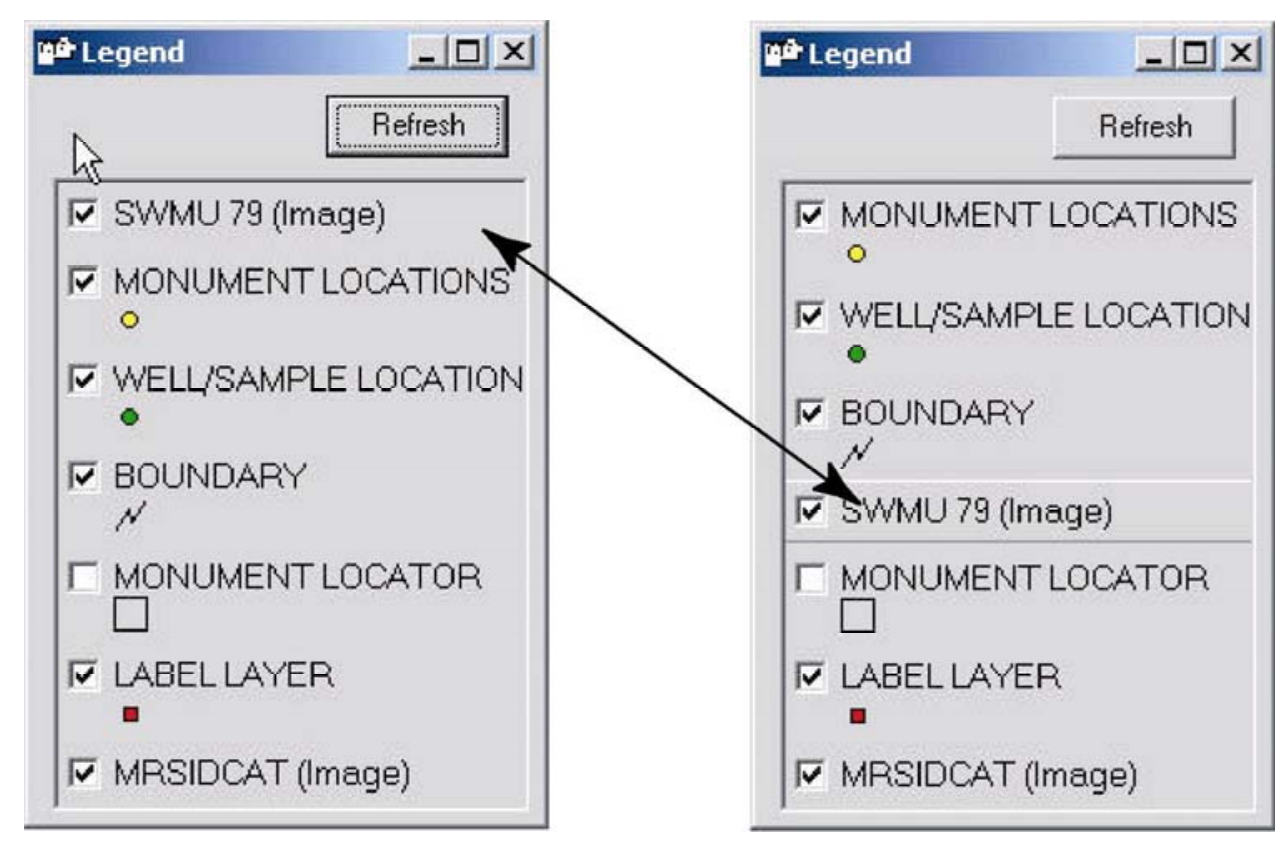

By using the Legend window, the image covering the monument locations can easily be adjusted by using the mouse cursor to drag the layer below the Well/Sample Location layer, as seen above.

Printing the Map View window

This section provides insight into printing and pasting the Map View window into other programs for printing and report generation purposes.

From the File menu on the toolbar, you can select the Print option to print directly to a local installed printer.

\section{NOTE: THIS IS NOT RECOMMENDED FOR PRINTING COLOR MAPS!}

To print color versions of the Map View window, use the Send Map to Clipboard option in the Tools menu.

1. After generating the map you would like to print or use for a report, select the Send Map to Clipboard option from the Tools menu on the toolbar. 


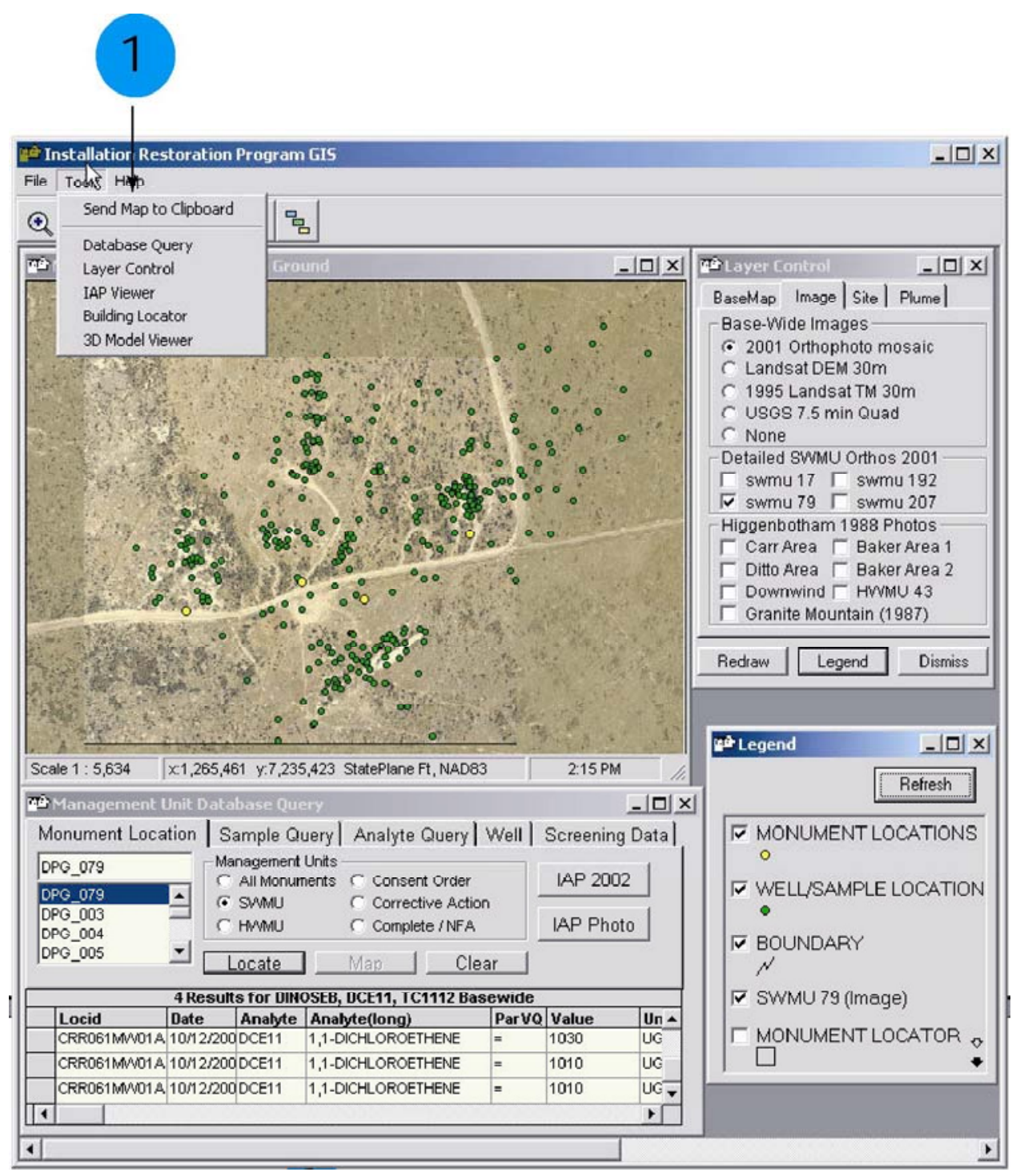

2. Open Microsoft Word or similar word processor.

3. From the Edit menu choose Paste. 


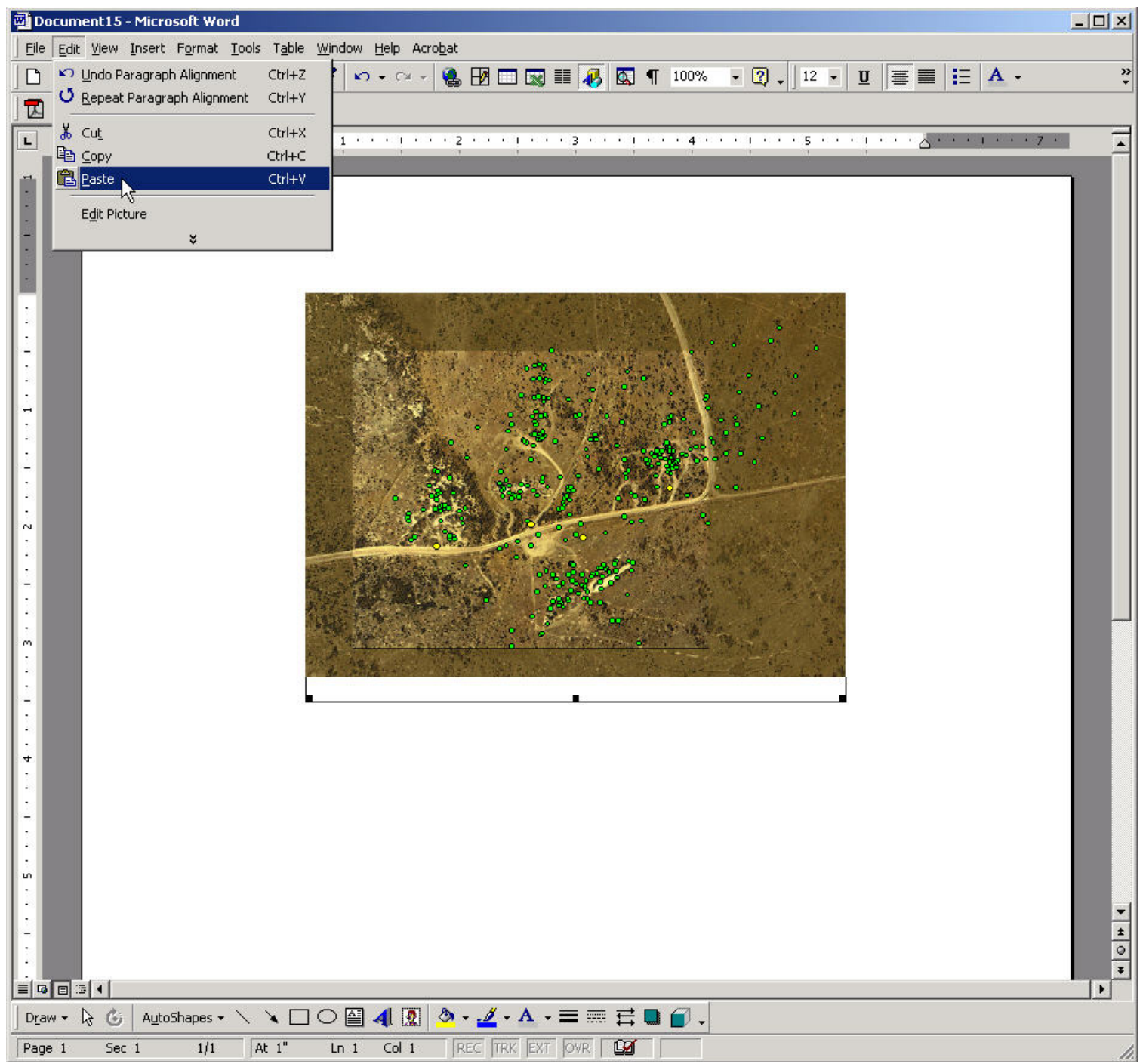

After pasting the image into Microsoft Word, it is easy to draw borders, center, scale, add arrows, etc., to highlight the features of interest. 


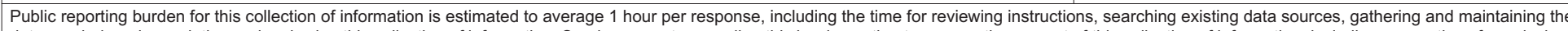

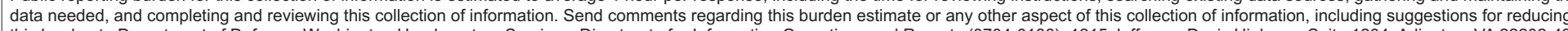

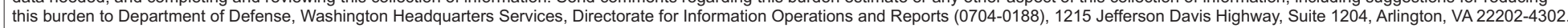

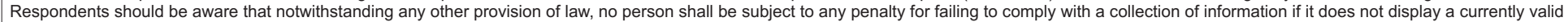
OMB control number. PLEASE DO NOT RETURN YOUR FORM TO THE ABOVE ADDRESS.
1. REPORT DATE (DD-MM-YY)
2. REPORT TYPE
July 2003
Special Report

4. TITLE AND SUBTITLE

3. DATES COVERED (From - To)

5a. CONTRACT NUMBER

Dugway Proving Ground Installation Restoration Program GIS:

5b. GRANT NUMBER

Software Documentation and Training Materials

5c. PROGRAM ELEMENT NUMBER

6. AUTHOR(S)

5d. PROJECT NUMBER

Paul T. Cedfeldt, Joel D. Schlagel, and David C. Finnegan

5e. TASK NUMBER

5f. WORK UNIT NUMBER

7. PERFORMING ORGANIZATION NAME(S) AND ADDRESS(ES)

8. PERFORMING ORGANIZATION REPORT

U.S. Army Engineer Research and Development Center

Cold Regions Research and Engineering Laboratory

72 Lyme Road

ERDC/CRREL SR-03-1

Hanover, NH 03755-1290

9. SPONSORING/MONITORING AGENCY NAME(S) AND ADDRESS(ES)

10. SPONSOR / MONITOR'S ACRONYM(S)

U.S. Army Dugway Proving Ground Installation Restoration Program, Dugway Proving Ground, Utah

11. SPONSOR / MONITOR'S REPORT NUMBER(S)

\section{DISTRIBUTION / AVAILABILITY STATEMENT}

Approved for public release; distribution is unlimited.

Available from NTIS, Springfield, Virginia 22161.

13. SUPPLEMENTARY NOTES

\section{ABSTRACT}

At the request of U.S. Army Dugway Proving Ground's Installation Restoration Program, the U.S. Army Engineer Research and Development Center's Cold Regions Research and Engineering Lab developed a Geographic Information System (GIS) for management and analysis of environmental restoration data. The GIS software can be used to compare and analyze datasets of diverse types, e.g., orthophotos, contaminant information stored in a database, and geospatial datalayers such as sample locations, roads, and buildings. Powerful chemical query capabilities allow the user to search for analytical results either basewide or at a particular site. Users can also query one or multiple contaminants by a specific detection threshold level, or return all sample results regardless of detection level. Query results can then be mapped to the screen to highlight clusters and/or possible contamination trends, or exported to a spreadsheet program. Hard-copy maps can also be printed from the software.

\begin{tabular}{ll}
\hline 15. SUBJECT TERMS & Dugway Proving Ground \\
& Environmental restorations \\
& GIS
\end{tabular}

16. SECURITY CLASSIFICATION OF:

a. REPORT

$\mathrm{U}$

b. ABSTRACT

$\mathrm{U}$

c. THIS PAGE

$\mathrm{U}$

\begin{tabular}{|} 
17. LIMITATION OF \\
OF ABSTRACT \\
U
\end{tabular}

18. NUMBER OF PAGES

45 